\title{
A computational methodology for effective bioclimatic-design applications in the urban environment
}

\author{
G.M. Stavrakakis ${ }^{\mathrm{a}, \mathrm{b}, *}$, E. Tzanaki ${ }^{\mathrm{c}}$, V.I. Genetzaki ${ }^{\mathrm{d}, 1}$, G. Anagnostakis ${ }^{\mathrm{c}}$, G. Galetakis ${ }^{\mathrm{c}}$, E. Grigorakis ${ }^{\mathrm{c}}$ \\ a 21 Filippou Str., GR-15344, Athens, Greece \\ b Computational Fluid Dynamics Unit, School of Chemical Engineering, National Technical University of Athens, GR-15780, Athens, Greece \\ c A2Ggreen Architects Ltd., 20 M. Agarathou \& Thalita Str., GR-71202, Heraclion, Greece \\ d 29 L. Mavili Str., GR-71306, Heraclion, Greece
}

\section{A R T I C L E I N F O}

\section{Keywords:}

Computational Fluid Dynamics

Urban Heat Island

Bioclimatic design

Thermal comfort

Bioclimatic maps

Evapotranspiration

\begin{abstract}
A B S T R A C T
In the present paper a computational methodology for assessing and improving the microclimate in the urban environment is developed. A Computational Fluid Dynamics (CFD) model is described, which accounts for the evaporation occurring on water surfaces as well as the evapotranspiration from plant surfaces and tree foliage. Solar radiation and wind effects are also taken into account. Additionally, thermal comfort indices are implemented in the model, hence local information is provided regarding thermal sensations (bioclimatic maps). Surface temperature and air temperature at pedestrian level, are also used to characterize the microclimate. The methodology is demonstrated by means of a case study, which refers to the area of Gazi in Greece. Initially, the model is applied for simulating the airflow pattern throughout the domain of interest. The numerical results reveal the problematic areas in terms of thermal discomfort and wind effects. Based on that information advanced bioclimatic techniques are suggested to reduce severe heat stresses and to eliminate these areas. The effectiveness of the architectural interventions is tested by estimating the microclimate-indices differences compared to the existing conditions. It is concluded that the proposed methodology serves adequately for applying effective bioclimatic strategies to mitigate the Urban Heat Island (UHI) effect.
\end{abstract}

(c) 2012 Elsevier B.V. All rights reserved.

\section{Introduction}

The Urban Heat Island (UHI) effect is related to higher urban temperatures in the city centers compared to the surrounding rural or suburban areas (Santamouris, Synnefa, \& Karlessi, 2011). This situation is mainly caused by anthropogenic heat releases in the urban environment, i.e. vehicles, power plants, air-conditioners and other heat sources, as well as by heat stresses produced by the use of ground or building materials of pour thermal behavior, the lack of heat sinks (water surfaces) and of vegetation (Memon, Leung, \& Chunho, 2008). The adverse effects of UHI include the deterioration of living environment and increase in energy consumption in buildings, especially during the summer period (Hassid et al., 2000).

Abbreviations: ABL, atmospheric boundary layer; ASHRAE, American Society of Heating Refrigerating and Air-Conditioning Engineers; CFD, Computational Fluid Dynamics; PMV, predicted mean vote; SET, standard effective temperature; SIMPLE, semi-implicit method for pressure-linked equations; UHI, Urban Heat Island.

* Corresponding author at: Filippou Str., GR-15344, Athens, Greece.

Tel.: +306946 467937 .

E-mail addresses: gstavr@mail.ntua.gr,george_stavrakakis@yahoo.com (G.M. Stavrakakis).

1 Architect, self employed.
This situation is even more intensive in areas of low income population (Santamouris, Pavlou, Synnefa, Niachou, \& Kolokotsa, 2007). Furthermore, UHI increases the generation of pollutants while the total ecological footprint is augmented (Fintikakis et al., 2011).

In parallel, the Kyoto protocol recommendations for reducing greenhouse emissions by at least $5 \%$ by 2008-2012 (Chlela, Hassaunndee, Inard, \& Riederer, 2009) in order to tackle global warming and climate change, has forced governments to focus on the reduction of energy consumption in buildings. One of the key factors to achieve this objective is by retrofitting and rehabilitating existing open public spaces so that the UHI effect is mitigated (Fintikakis et al., 2011).

In order to limit the effect of heat islands on energy demands and summer comfort, various techniques have been proposed involving the use of reflective materials, increased plantation and the use of heat sinks (Akbari, Davis, Dorsano, Huang, \& Winert, 1992; Fintikakis et al., 2011). Numerous studies that report optical and thermal characteristics of construction materials and their influence on urban environment exist (Akbari et al., 1992; Doulos, Santamouris, \& Livada, 2001; Fintikakis et al., 2011; Niachou, Livada, \& Santamouris, 2008; Santamouris et al., 2011; White, Golden, Biligiri, \& Kaloush, 2010). In most of these studies it becomes evident that the use of materials with high reflectivity 


\begin{tabular}{|c|c|}
\hline \multicolumn{2}{|c|}{ Nomenclature } \\
\hline$a b s$ & absorptivity \\
\hline$a l b$ & albedo \\
\hline$C_{\mu}$ & turbulent viscosity coefficient \\
\hline$C P$ & cooling power \\
\hline$D_{j}$ & water-vapor mass diffusion coefficient $\left(\mathrm{m}^{2} / \mathrm{s}\right)$ \\
\hline$e^{j}$ & expectancy factor \\
\hline E & evaporation rate $\left(\mathrm{kg} / \mathrm{m}^{2} \mathrm{~s}\right)$ \\
\hline$f$ & Blasius friction factor \\
\hline$F(u)$ & velocity function $\left(\mathrm{kg} / \mathrm{Pa} \mathrm{m}^{2} \mathrm{~s}\right)$ \\
\hline$f_{L}$ & cloudiness factor \\
\hline$h_{c}$ & convective heat transfer coefficient $\left(\mathrm{W} / \mathrm{m}^{2} \mathrm{~K}\right)$ \\
\hline$H_{\max }$ & maximum building height $(\mathrm{m})$ \\
\hline$i$ & latitude $\left(^{\circ}\right)$ \\
\hline$I_{c l}$ & clothing insulation, clo \\
\hline$K$ & turbulence kinetic energy $\left(\mathrm{m}^{2} / \mathrm{s}^{2}\right)$ \\
\hline$K_{\text {air }}$ & heat conduction coefficient $(\mathrm{W} / \mathrm{m} \mathrm{K})$ \\
\hline$K_{l}$ & leaf-shape parameter \\
\hline$L_{n}$ & longwave radiation $\left(\mathrm{W} / \mathrm{m}^{2}\right)$ \\
\hline Met & metabolic rate $\left(\mathrm{W} / \mathrm{m}^{2}\right)$ \\
\hline PMV & predicted mean vote \\
\hline$p_{s}$ & saturated water vapor pressure $(\mathrm{Pa})$ \\
\hline$p_{v}$ & water vapor pressure $(\mathrm{Pa})$ \\
\hline$R$ & infrared radiation $\left(\mathrm{W} / \mathrm{m}^{2}\right)$ \\
\hline$r_{b l}$ & leaf boundary layer resistance $(\mathrm{s} / \mathrm{m})$ \\
\hline & leaf cuticular resistance $(\mathrm{s} / \mathrm{m})$ \\
\hline$R H_{\text {imag }}$ & relative humidity in the imaginary environment (\%) \\
\hline & leaf intercellular air space resistance (s/m) \\
\hline$R_{n}$ & total radiation $\left(\mathrm{W} / \mathrm{m}^{2}\right)$ \\
\hline$r_{s t}$ & leaf stomatal resistance $(\mathrm{s} / \mathrm{m})$ \\
\hline$S_{\text {diffuse }}$ & leaf diffuse radiation $\left(\mathrm{W} / \mathrm{m}^{2}\right)$ \\
\hline$S_{\text {direct }}$ & leaf absolute incident radiation $\left(\mathrm{W} / \mathrm{m}^{2}\right)$ \\
\hline SET & standard effective temperature $\left({ }^{\circ} \mathrm{C}\right)$ \\
\hline$S_{n}$ & $\begin{array}{l}\text { sum of entering and reflective shortwave radiation } \\
\left(\mathrm{W} / \mathrm{m}^{2}\right)\end{array}$ \\
\hline$S_{\varphi}$ & source term in the conservation equation \\
\hline$t$ & time $(s)$ \\
\hline$T_{\text {in }}$ & temperature at the inlet boundary $\left({ }^{\circ} \mathrm{C}\right)$ \\
\hline$T_{l}$ & leaf temperature $\left({ }^{\circ} \mathrm{C}\right)$ \\
\hline$u$ & velocity magnitude of the air $(\mathrm{m} / \mathrm{s})$ \\
\hline$u *$ & friction velocity $(\mathrm{m} / \mathrm{s})$ \\
\hline$u_{2 m}$ & velocity magnitude $2 \mathrm{~m}$ above the ground $(\mathrm{m} / \mathrm{s})$ \\
\hline$u_{f}$ & $\begin{array}{l}\text { free-stream Velocity magnitude above the height of } \\
\text { the atmospheric boundary layer }(\mathrm{m} / \mathrm{s})\end{array}$ \\
\hline$u_{r e f}$ & $\begin{array}{l}\text { velocity magnitude at the height of meteorological- } \\
\text { station sensor }(\mathrm{m} / \mathrm{s})\end{array}$ \\
\hline$u_{x}$ & velocity component in $x$ direction $(\mathrm{m} / \mathrm{s})$ \\
\hline & velocity component in $y$ direction $(\mathrm{m} / \mathrm{s})$ \\
\hline & velocity component in $z$ direction $(\mathrm{m} / \mathrm{s})$ \\
\hline & leaf length aligned to air direction (m) \\
\hline \multicolumn{2}{|c|}{$\begin{array}{l}\text { Wind }_{\text {index }} \text { index of mechanical wind effects on pedestrians } \\
(\mathrm{m} / \mathrm{s})\end{array}$} \\
\hline$Y_{\mathrm{H}_{2} \mathrm{O}}$ & water vapor mass fraction $\left(\mathrm{kg} / \mathrm{kg}_{\text {mixture }}\right)$ \\
\hline$Y_{\mathrm{H}_{2} \mathrm{O}, \text { in }}$ & $\begin{array}{l}\text { water vapor mass fraction at the inlet boundary } \\
\left(\mathrm{kg} / \mathrm{kg}_{\text {mixture }}\right)\end{array}$ \\
\hline$z$ & arbitrary height from ground (M) \\
\hline & height of the meteorological-station sensor (M) \\
\hline \multicolumn{2}{|c|}{ Greek letters } \\
\hline$\rho$ & density $\left(\mathrm{kg} / \mathrm{m}^{3}\right)$ \\
\hline & transported variable in the conservation equation \\
\hline & diffusion coefficient in the conservation equation \\
\hline$\varepsilon$ & turbulent kinetic energy dissipation rate $\left(\mathrm{m}^{2} / \mathrm{s}^{3}\right)$ \\
\hline
\end{tabular}

\begin{tabular}{|ll|}
\hline & \\
$\eta$ & relative sunlight duration hours \\
$\hat{\theta}$ & wind direction $\left(^{\circ}\right)$ \\
$\delta$ & atmospheric boundary layer height $(\mathrm{M})$ \\
$\alpha$ & roughness term in the exponential law \\
$\kappa$ & Von Karman constant \\
$\tau_{0}$ & wall shear stress $(\mathrm{Pa})$ \\
$\mu$ & dynamic molecular viscosity $(\mathrm{kg} / \mathrm{m} \mathrm{s})$ \\
$\Delta$ & water vapor saturation curve gradient $\left(\mathrm{Pa} /{ }^{\circ} \mathrm{C}\right)$ \\
$\gamma$ & psychrometric coefficient $\left(\mathrm{Pa} /{ }^{\circ} \mathrm{C}\right)$ \\
$\lambda$ & evaporation latent heat $(\mathrm{J} / \mathrm{kg})$ \\
$\varepsilon_{n}$ & dimensionless coefficient in the longwave radiation \\
$\sigma$ & equation \\
$\sigma_{u}$ & Stefan-Boltzmann constant $\left(\mathrm{W} / \mathrm{m}^{2} \mathrm{~K}^{4}\right)$ \\
$\omega$ & standard deviation of air velocity magnitude \\
$\rho_{l}$ & leaf orientation to the sun's direct beam $\left({ }^{\circ}\right)$ \\
$\rho_{a}$ & water vapor density on leaf surface $\left(\mathrm{kg} / \mathrm{m}^{3}\right)$ \\
$\delta_{b l}$ & water vapor density in the air $\left(\mathrm{kg} / \mathrm{m}^{3}\right)$ \\
Subscripts & \\
$b l$ & boundary layer thickness on leaf surface $(\mathrm{M})$ \\
$c$ & convection \\
$c l$ & cloth \\
$i a s$ & intercellular air space \\
$i n$ & inlet \\
$l$ & leaf \\
$m a x$ & maximum \\
$r e f$ & reference \\
$s$ & saturated \\
$s t$ & stomatal \\
$v$ & vapor \\
& \\
\hline
\end{tabular}

to solar radiation and high spectral emissivity, the so-called cool materials, increase the urban albedo and it is considered as one of the most promising technique to tackle the UHI phenomenon. Additionally, increasing green spaces and vegetation represents a powerful mitigation technique as it contributes in heat-stress relaxation, blocking noise and wind protection (Fintikakis et al., 2011). Furthermore, the use of heat sinks, i.e. water surfaces (fountains and water streams), represents an adequate technique to dissipate part of the excessive urban heat.

The state of the art provided from current international research indicates methods to build sustainable environments in the urban sector. Modern landscape and urban architecture has moved on from empirical design techniques and it requires accurate methods to quantify microclimate for assessing and improving climatic conditions in cities. Computational Fluid Dynamics (CFD) models have gained interest for such purposes as a result of gradual upgrade of computational resources. Numerous investigations in literature indicate that CFD models serve well for bioclimaticdesign applications. Priyadarsini, Hien, and David (2008) presented a survey of CFD simulations for assessing the UHI effect in Singapore and highlighted the significance of using reflective materials on building facades, while proper arrangement of high-rise towers for enhancing airflow within street canyons is suggested. Fintikakis et al. (2011) presented various UHI mitigation tactics that were tested using a coupled CFD and an experimental procedure, by means of imposing surface-temperature measurements as boundary conditions in the CFD model. In the absence of such measurements Takahashi, Yoshida, Tanaka, Aotake, and Wang (2004) developed a simulation code for predicting solid-surfaces temperatures by combining CFD computations with surface radiation exchange and unsteady heat conduction calculations. The influence 
of the outdoor microclimate on building energy consumption is quantified by Bouyer, Inard, and Musy (2011), who presented a CFD-thermoradiative coupled simulation tool for estimating building energy demands with respect to different urban design scenarios. The influence of trees and water ponds on urban microclimate was numerically examined by Robitu, Musy, Inard, and Groleau (2006), who introduced a coupled CFD-radiation model for simulating heat and mass transfer mechanisms, such as evaporation and evapotranspiration.

The present paper addresses the issues discussed in the investigations above and it presents an integrated computational approach for predicting and mitigating the UHI effect. The main contribution of the present study is the development of a detailed methodology towards the formulation of specific technical instructions for designing open spaces in the urban environment that ensure thermal comfort conditions at pedestrian level. The methodology proposed includes most important physical processes of the airflow phenomenon in the building complex as well as personal parameters to evaluate thermal comfort. The key delivery of the present study is the provision of a practical and robust approach for urban planning purposes. The methodology developed involves the application of a validated CFD model for predicting the microclimate in the urban sector and advanced rehabilitation techniques to improve pedestrians' thermal comfort as well as to reduce areas of high temperatures.

\section{Methodology}

A concise description of the procedure presented herein is formulated as follows: Initially, the existing microclimatic conditions are estimated by applying a CFD model with respect to the governing climatic parameters, extracted by statistical processing of available meteorological data. The model includes solar radiation effects as well as special source terms in mass and energy conservation equations to account for evaporation and evapotranspiration. Thermal sensations of pedestrians are computed by implementing special thermal comfort indices in the CFD model. The numerical results obtained are utilized to identify areas of high temperatures, thermal discomfort and excessive wind speed. Accordingly, architectural interventions (e.g. cool materials, shading devices, vegetation, water and plant surfaces) are introduced to eliminate these conditions. Finally, the CFD model is executed for the modified version of the area and the effectiveness of the interventions suggested is tested in terms of microclimate-parameters differences compared to the existing situation.

\section{The case study considered}

The case study considered constitutes of two squares and of their connection road, which are situated in the area of Gazi in Heraclion, Greece. The geographic coordinates of the urban space are: Latitude of $35.1931^{\circ}$ and Longitude of $25.0401^{\circ}$, while its height from sea level ranges from $20 \mathrm{~m}$ to $35 \mathrm{~m}$. The distance from sea coast is $1500 \mathrm{~m}$. As far as the weather conditions are concerned, a temperate Mediterranean climate dominates, which corresponds to hot and dry summers and cool, humid winters. The greater urban area of interest and the spaces where bioclimatic-design interventions are proposed are presented in Fig. 1.

The specific area suffers from various environmental problems due to the rapid growth of building construction and of traffic in the last years. This situation results in the gradual increase of anthropogenic heat, which, in combination with the use of conventional

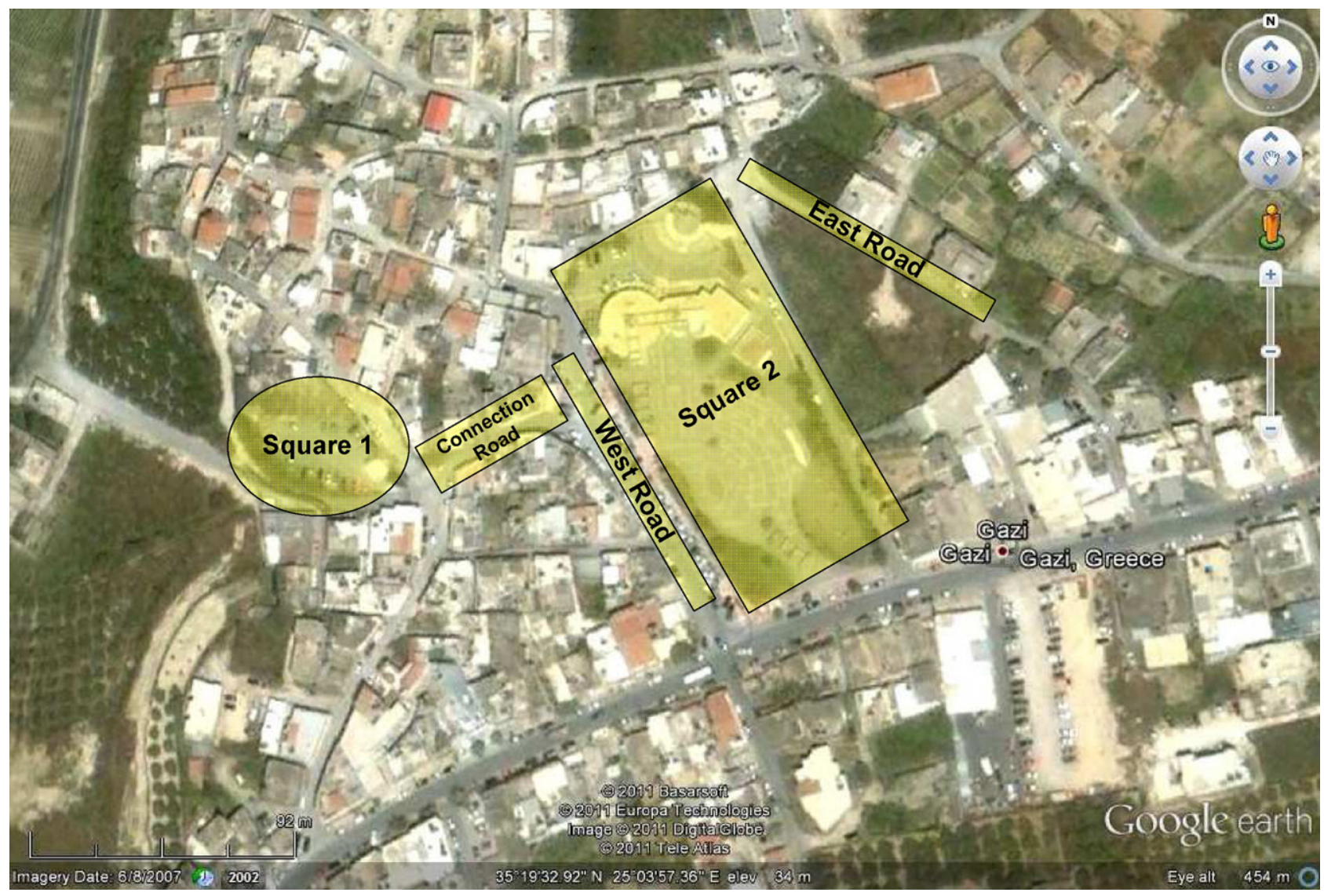

Fig. 1. Area of interest. 


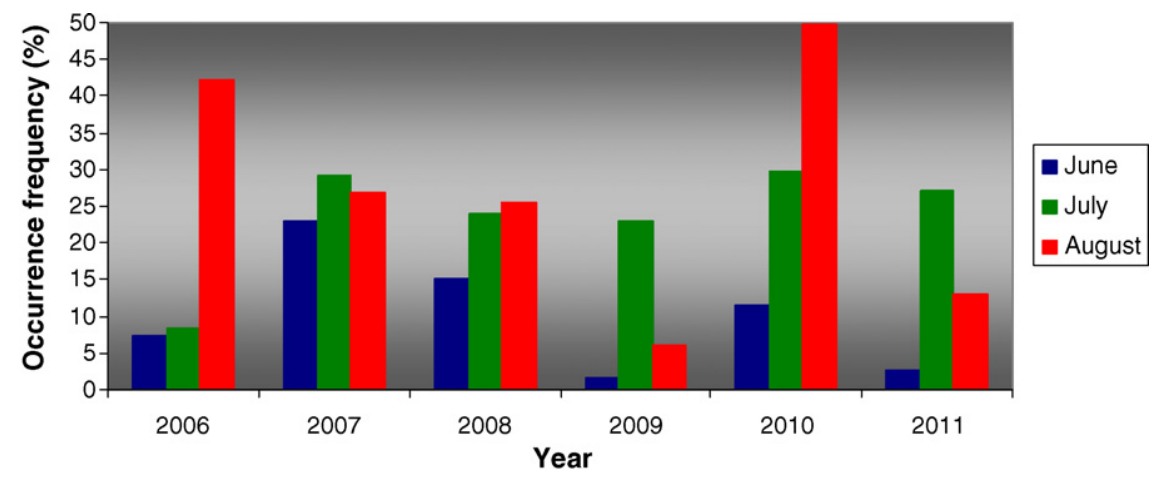

Fig. 2. Occurrence frequency of temperatures above threshold value.

building and ground materials, e.g. concrete pavers and asphalt, contributes to the increase of temperature and comfort-level degradation of pedestrians. As a consequence, the energy consumed in the neighboring buildings increases for cooling purposes. Finally, it should not be disregarded that the area suffers from relatively strong winds, as indicated by the available meteorological data and by citizens' complaints.

The surfaces, where bioclimatic-design interventions are proposed, are adumbrated in Fig. 1 and they are consisting of the characteristics below:
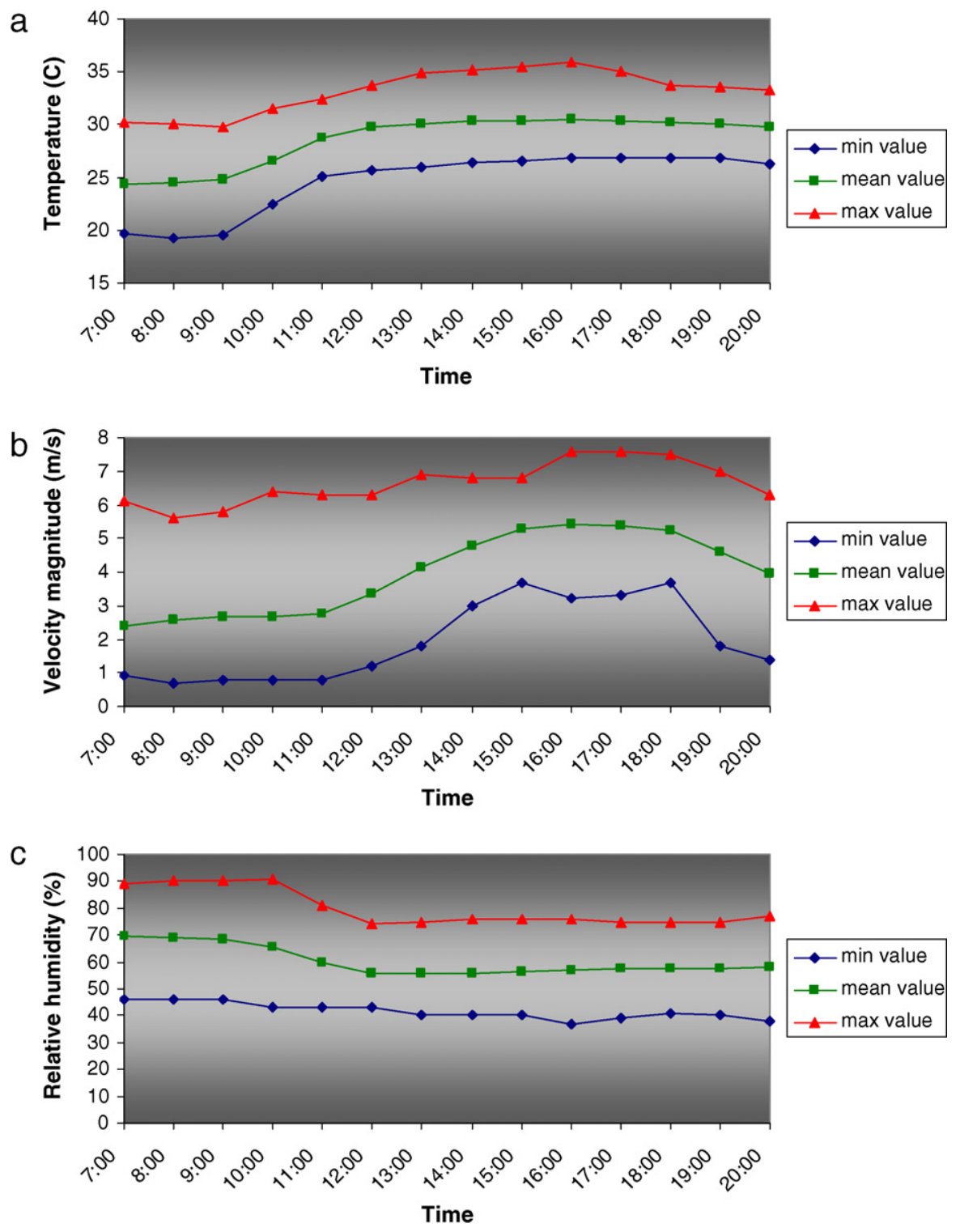

Fig. 3. Mean and uttermost values for: (a) temperature, (b) wind speed and (c) relative humidity. 


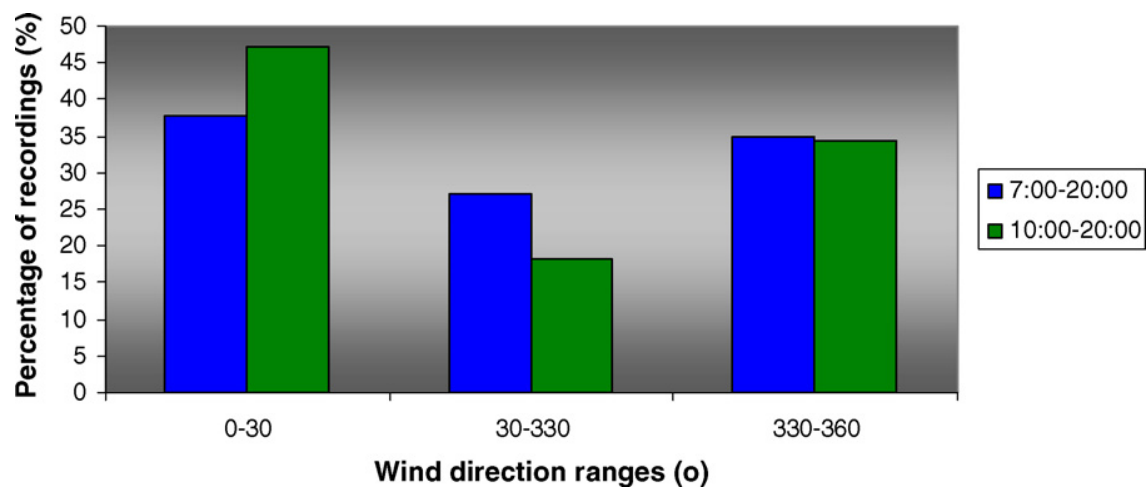

Fig. 4. Percentage of recordings of wind-direction ranges.

- Square 1: The building existing in the square is a concrete construction of dark gray color. The ground material is conventional asphalt, while no artificial or physical (trees) shading devices are present. The material used in the south and the west road is also conventional asphalt. The east passage of the square is covered with conventional concrete pavers of dark gray color.

- Connection road of the squares: The ground surface is covered with conventional concrete pavers of dark gray color, while trees and shading devices are absent.

- West road of the square 2: The ground covering is conventional concrete paver.

- Square 2: The square includes the city hall building, which consists of two substructures connected via a semi-outdoor space in the middle of the building, and a cafeteria. Both buildings are concrete constructions of beige color. The main material used for ground covering is concrete paver of gray color, while some linings of red paver exist. In the southwest part of the square a grass parterre exists, where few trees are present. In the southeast part a play-ground is situated using sand as ground covering, where a cypress cluster is also present. The pergolas existing in the square are currently unexploited. In the north part of the square a small auditorium of gray concrete is built, while plantation is limited. The east adjacent passage is of conventional asphalt.

- East Road of square 2: Conventional asphalt road.

\section{Meteorological data}

The weather data used to characterize the local climate are received from the meteorological station situated on the roof of the city-hall building. The available data base includes hourly recordings of temperature, relative humidity, wind speed and direction for the last six years. Obviously, the limited data base is not capable of leading to conclusions regarding climate change. However, it can be used for extracting the dominating climate parameters which correspond to the worst scenario in terms of hot conditions. The statistical procedure followed aims at determining climate-parameter values on a hot summer day.

Initially, the recordings of the summer months are gathered and the occurrence frequency of heat waves is determined for each month every year. This is achieved by calculating the percentage of temperature recordings that exceed a threshold value (at present a value of $30^{\circ} \mathrm{C}$ is set). The results are illustrated in Fig. 2 and it is concluded that the hottest conditions occurred in August 2010 as the occurrence frequency of heat waves was approximately $50 \%$. Hence, the weather conditions recorded during that period represent the worst case scenario, which is likely to reoccur in the future. The mean and uttermost values of climate parameters that correspond to August 2010, for each hour from 7.00 to 20.00 are presented in Fig. 3.

As far as wind direction at the specific period is concerned, it is determined according to the hypothesis that all directions diverging by $\pm 30^{\circ}$ from strictly north direction are considered north. The percentage of recordings of specific wind-direction ranges are presented in Fig. 4. It is seen that the percentage of north-direction recordings is $73 \%$ during the time period $7.00-20.00$. Especially during the time period $10.00-20.00$, in which heat stresses are expected, the percentage of north-direction recordings is approximately $81 \%$. It is concluded that the north direction is dominant during the time period 7.00-20.00. The representative weather data extracted herein (see Fig. 3) are summarized in Table 1 and they are used as inlet boundary conditions in the CFD model.

\section{Mathematical modeling}

\subsection{Governing equations}

The present CFD model applies numerical techniques to solve the conservation equations for a three-dimensional turbulent fluid flow, which can be cast in the following general form (Patankar, 1980):

$\frac{\partial(\rho \varphi)}{\partial t}+\operatorname{div}\left(\rho \vec{u}-\Gamma_{\varphi} \operatorname{grad} \varphi\right)=S_{\varphi}$

where $\rho$ is the density of the mixture air-water vapor; $\vec{u}$ is the velocity vector; $\varphi$ is the dependent variable being 1 for the continuity equation, $u_{x}, u_{y}, u_{z}$ for the momentum equation in $x, y$ and $z$ direction, respectively, $T$ for the equation of energy and $Y_{\mathrm{H}_{2} \mathrm{O}}$ for the water-vapor transfer equation; $\Gamma_{\varphi}$ is the diffusion coefficient of

Table 1

Representative climate-parameter values of incoming wind.

\begin{tabular}{|c|c|c|c|c|c|c|c|}
\hline Parameter & $7: 00$ & $8: 00$ & $9: 00$ & $10: 00$ & 11:00 & $12: 00$ & $13: 00$ \\
\hline Wind speed $(\mathrm{m} / \mathrm{s})$ & 2.41 & 2.55 & 2.64 & 2.65 & 2.75 & 3.37 & 4.12 \\
\hline Temperature $\left({ }^{\circ} \mathrm{C}\right)$ & 24.38 & 24.44 & 24.75 & 26.56 & 28.80 & 29.74 & 30.12 \\
\hline Relative humidity (\%) & 69.38 & 69.19 & 68.16 & 69.38 & 69.19 & 68.16 & 65.29 \\
\hline Parameter & $14: 00$ & $15: 00$ & $16: 00$ & $17: 00$ & $18: 00$ & 19:00 & $20: 00$ \\
\hline Wind speed $(\mathrm{m} / \mathrm{s})$ & 4.79 & 5.26 & 5.40 & 5.39 & 5.25 & 4.60 & 3.97 \\
\hline Temperature $\left({ }^{\circ} \mathrm{C}\right)$ & 30.40 & 30.38 & 30.48 & 30.34 & 30.19 & 30.11 & 29.75 \\
\hline Relative humidity (\%) & 59.58 & 56.00 & 55.80 & 55.80 & 56.45 & 57.70 & 58.06 \\
\hline
\end{tabular}



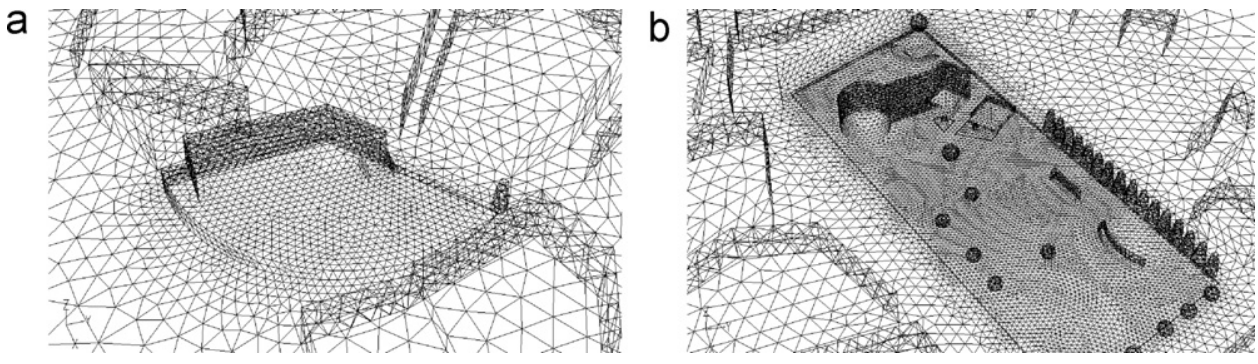

Fig. 5. Spatial discretization of the existing situation in: (a) square 1 and (b) square 2 .

variable $\varphi$; and $S_{\varphi}$ is the source/sink term of variable $\varphi$. The transferred quantity $\varphi$, also stands for turbulence dependent variables, here for the kinetic energy of turbulence $k$ and for the eddy dissipation rate $\varepsilon$. In this study the standard $k-\varepsilon$ model (Launder \& Spalding, 1974) is applied, which is modified to account for buoyancy effects (Stavrakakis \& Markatos, 2009). The model treats flow effects in the vicinity of the walls using standard wall functions (Launder \& Spalding, 1972).

The assumptions made for the problem are:

(a) Incompressible flow of a Newtonian fluid,

(b) Neutral atmospheric conditions,

(c) Richards-Hoxey assumptions for the Atmospheric Boundary Layer (ABL) (Richards \& Hoxey, 1993),

(d) The fluid is considered as a mixture of dry air and water vapor. The diffusion coefficients as well as the physical properties of the mixture may be found in previous investigations (Stavrakakis, Koukou, Vrachopoulos, \& Markatos, 2008; Stavrakakis, Stamou, \& Markatos, 2009; Stavrakakis, Zervas, Sarimveis, \& Markatos, 2010).

(e) Traffic conditions in the area are currently neglected and only the effect of construction materials and physical elements is taken into account. However, the results obtained are considered adequate for interpreting the difference in microclimate parameters before and after the architectural intervention.

The CFD model applied herein is validated, at least regarding velocity components and temperature variations, in recent studies (Stavrakakis \& Markatos, 2009; Stavrakakis et al., 2008, 2011).

\subsection{Computational domain, grid and method of solution}

The problem follows the general theoretical aspects regarding the airflow around bluff bodies (Ferziger \& Peric, 2002). According to literature guidelines the computational domain is built so that important flow effects, such as the so-called "horse-shoe" vortex (Ferziger \& Peric, 2002), are properly simulated. Specifically, the inlet boundary, the lateral and the upper boundaries are placed at a distance of $4 H_{\max }$ from the building complex, while the outlet boundary is located $8 H_{\max }$ far from the area of interest (where $H_{\max }$ is the maximum building height of the domain).

The computational domain is discretized by applying a non uniform unstructured grid. The computational grid contains approximately 350,000 and 450,000 control volumes for the situations before and after the architectural intervention, respectively, whilst the scale of spatial resolution reaches $0.2 \mathrm{~m}$ near small wall surfaces. The grids of the existing and the suggested situation are illustrated in Figs. 5 and 6, respectively.

The CFD code used employs a standard finite-volume method provided by a general CFD platform (Fluent v.6.3.26). The first-order upwind discretization scheme and the SIMPLE solution algorithm (Versteeg \& Malalasekera, 1995) are used, while residuals of $10^{-4}$, for pressure, velocity and turbulence components, and of $10^{-7}$ for enthalpy and chemical species, are set for full convergence. Simulations are performed on a Windows PC of $2.0 \mathrm{GHz} C P U$ and of $3 \mathrm{~GB}$ RAM. The solution time is approximately $1 \mathrm{~h}$ and $1.5 \mathrm{~h}$ for each hour reported in Table 1 (from sunrise to sunset), for the existing and the suggested case, respectively.

\subsection{Incident solar radiation}

The incident solar radiation on solid surfaces is computed using the solar ray tracing model (Fluent Inc., 2005). The amount of solar load depends on the material optical properties (albedo and transmissivity for semi-transparent surfaces) and it is determined by applying a special solar load model, namely Solar Position and Intensity Code (Solpos) developed in the American National Renewable Energy Laboratory (NREL) (http://rredc.nrel.gov/solar/codesandalgorithms/solpos/). The model calculates the direction of solar beam with respect to the day and hour of interest for the given geographical coordinates (reported in Section 3 above); thus the solar load on the wall surfaces is calculated for each hour from sunrise to sunset. It should be mentioned that the model also accounts for cloud cover conditions by implementing a cloudiness factor, defined in the equation below:

$f_{L}=0.1+0.9 \eta$
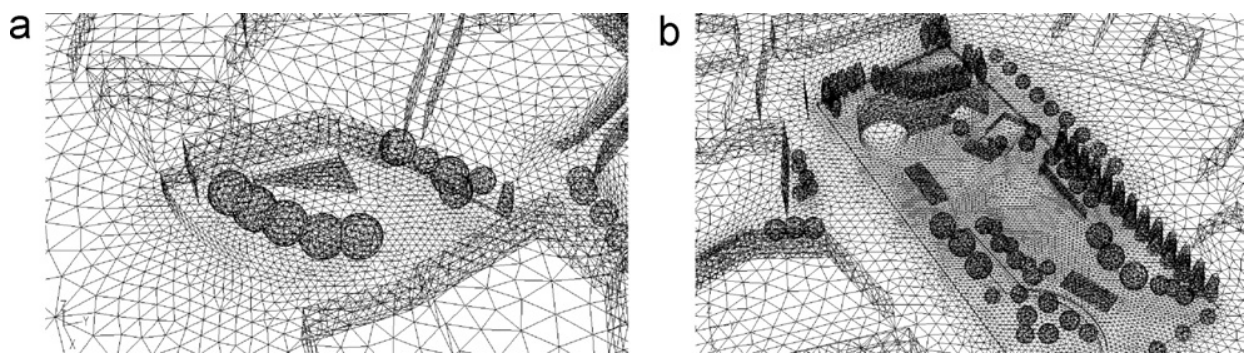

Fig. 6. Spatial discretization of the suggested situation in: (a) square 1 and (b) square 2 . 
where $\eta$ is the relative sunlight term defined as the ratio of actual and theoretical sunlight duration hours. In the present study the value 1.0 is set for summer conditions.

\subsection{Boundary conditions and special sources}

\subsubsection{Inlet boundary}

At the inlet boundary, the exponential law for velocity components is imposed. In the general case of oblique flow the following equations are used:

$u_{x}=\frac{u_{r e f} \sin \hat{\theta}}{\left(z_{r e f} / \delta\right)^{a}}\left(\frac{z}{\delta}\right)^{a}$

$u_{y}=\frac{u_{r e f} \cos \hat{\theta}}{\left(z_{\text {ref }} / \delta\right)^{a}}\left(\frac{z}{\delta}\right)^{a}$

The equations above are obtained by combining the equations of velocity at the ABL height $\delta$, being $300 \mathrm{~m}$ from ground, and at a reference height $z_{\text {ref }}$, e.g. the meteorological-sensor height, where the velocity of incoming wind $u_{\text {ref }}$ is available for each hour (Table 1) (Stavrakakis et al., 2009). The term $a$ stands for the terrain roughness, which is set equal to 0.2 (Cook, 1997), and $z$ is an arbitrary height from ground. Finally, the height of the weather-station sensor is $33 \mathrm{~m}$ above sea level, while the wind incidence angle $\hat{\theta}$ (Stavrakakis et al., 2009) is set equal to zero as explained in Section 4.

As far as the turbulence components are concerned they are imposed using the equations below (according to the assumption (c) above):

$k=\frac{u_{*}^{2}}{\sqrt{C_{\mu}}}\left(1-\frac{z}{\delta}\right)$

$\varepsilon=\frac{u_{*}^{3}}{\kappa z}$

where $\kappa$ is the Von Karman constant and $u_{*}$ is the friction velocity. The latter is calculated as follows:

$u_{*}=\left(\frac{\tau_{0}}{\rho}\right)^{1 / 2}$

where $\tau_{0}$ is the wall shear stress defined by the equation below:

$\tau_{0}=\frac{f \rho u_{f}^{2}}{2}$

where $u_{f}$ is the velocity at the ABL height $\left(u_{f}=u_{r e f}\left(\delta / z_{r e f}\right)^{a}\right)$ and $f$ is the friction coefficient calculated by the Blasius equation (Stavrakakis et al., 2008):

$f=0.045\left(\frac{\rho u_{f} \delta}{\mu}\right)^{-1 / 4}$

According to the assumption (b) reported above, a constant temperature $T_{\text {in }}$ is set, received by Table 1 for each hour considered. Water-mass fraction is also set at a constant value with respect to relative-humidity $(R H)$ values tabulated in Table 1 . Specifically, it is calculated as follows (Perry \& Green, 1999):

$Y_{\mathrm{H}_{2} \mathrm{O}, \text { in }}=\frac{0.622 p_{v}}{P-0.378 p_{v}}$

where $p_{v}$ is the water vapor pressure:

$p_{v}=R H \times \frac{p_{s}}{100}$

and $p_{s}$ is the saturated water vapor pressure:

$p_{s}=\frac{10^{5}}{760} \exp \left(18.3-\frac{3816.44}{226.87+T_{\text {in }}}\right)$
The aforementioned model is implemented in the CFD model as a user-defined function based on a special $\mathrm{C}++$ code.

\subsubsection{Outlet, lateral and upper boundaries}

The outlet boundary is handled so that horizontal homogeneity is retained for all variables considered and no reverse flow occurs, i.e. a Neumann condition is imposed for the transferred quantity, $\partial \varphi / \partial x_{j j}=0(\vec{j} j / / \vec{n}$, where $\overrightarrow{j j}$ is the velocity direction vector and $\vec{n}$ is the defining normal-to-surface vector of the boundary). The upper and lateral boundaries are handled as free-slip boundaries, i.e. zero normal velocity component and zero normal spatial gradient of all other variables are imposed $\left(u_{j j}=0, \partial \varphi / \partial x_{j j}=0\right)$.

\subsubsection{Wall boundaries and special sources}

The airflow near walls is simulated using the well-known equilibrium wall functions for bridging the viscous and the inertial sublayer; thus ensuring the interconnection of all variables stored in wall-neighboring grid-nodes with their corresponding ones imposed on wall surfaces (Launder \& Spalding, 1972). Wall surfaces are handled as heat and water-vapor sources (or sinks) to account for special physical mechanisms, such as evaporation and evapotranspiration.

Specifically, the convective and radiative heat fluxes are obtained based on the thermal and optical properties of ground and building materials. Water surfaces represent heat sinks and watervapor sources through evaporation. Similarly, vegetation and plant surfaces represent water-vapor sources due to evapotranspiration, while they absorb solar radiation and convective heat at the shaded parts. In the subsections below the manipulation of the aforementioned special sources is analyzed in detail. The models presented below are applied as heat or/and mass sources (where appropriate) in the CFD model in the form of special user-defined functions based on a $\mathrm{C}++$ code.

\subsubsection{Water surfaces}

The evaporation rate is calculated according to Penman's method (Penman, 1948) as follows:

$E=\frac{\Delta}{\Delta+\gamma} \frac{R_{n}}{\lambda}+\frac{\gamma}{\Delta+\gamma} F(u) D$

where $E$ is the evaporation rate, $\gamma$ is the psychrometric coefficient, $\Delta$ is the slope of water-vapor saturation curve, $R_{n}$ is the total radiative heat flux, $\lambda$ is the evaporation latent heat, $F(u)$ is the velocity function and $D$ is the saturation vapor-pressure deficit $\left(D=p_{s}-p_{v}\right)$.

The terms $\gamma, \Delta, \lambda$ and $F(u)$ are defined by the Eqs. (14)-(17) below:

$\gamma=\frac{17.271 T_{\text {in }}}{237.7+T_{\text {in }}}+\ln \left(\frac{R H}{100}\right)$

$\Delta=\frac{4.098 \times 10^{5} p_{s}}{\left(T_{\text {in }}+237.3\right)^{2}}$

$\lambda=10^{3}\left(2501-2.361 T_{\text {in }}\right)$

$F(u)=7.2 \times 10^{-3}\left(1+0.54 u_{2 m}\right)$

where $u_{2 m}$ is the velocity of the incoming wind $2 \mathrm{~m}$ above the ground and the terms $p_{s}$ and $p_{v}$ are calculated with respect to the given relative humidity (Eqs. (11) and (12)).

The radiative heat balance on water surfaces is formulated as follows:

$R_{n}=S_{n}-L_{n}$

where $S_{n}$ is the algebraic sum of Entering and reflective shortwave radiation and $L_{n}$ is the longwave radiation. The aforementioned fluxes are calculated by Eqs. (19) and (20) below:

$S_{n}=(1-a l b) S_{0}(0.29 \cos i+0.55 \eta)$ 
$L_{n}=\varepsilon_{n} f_{L} \sigma\left(T_{i n}+273\right)^{4}$

where $a l b$ is the water albedo (0.06), $i$ is the latitude of the area (Section 3$), S_{0}$ is the extraterrestrial irradiation $\left(1367 \mathrm{~W} / \mathrm{m}^{2}\right.$ ) (Jain, 1988), $\sigma$ is the Stefan-Boltzmann constant and $\varepsilon_{0}$ is a dimensionless coefficient defined as follows:

$\varepsilon_{n}=0.56-0.08 p_{v}^{0.5}$

The evaporation model described above is applied on water surfaces in the CFD model; thus different evaporation fluxes are obtained for different climate-parameters combinations (velocity, temperature and relative humidity) that correspond to a certain hour of the day.

\subsubsection{Plantation surfaces}

The evaporation from plantation surfaces is estimated using Eq. (13) above, the terms $\gamma$ and $F(u)$ being modified as follows (Monteith, 1965):

$\gamma=\left(1+0.33 u_{2 m}\right)\left[\frac{17.271 T_{\text {in }}}{237.7+T_{\text {in }}}+\ln \left(\frac{R H}{100}\right)\right]$

$F(u)=\frac{2.5 u_{2 m}}{T_{\text {in }}+275}$

The rest of the parameters participating in the model are computed as described in the previous subsection, while the albedo term is altered to a higher value $(0.25)$.

\subsubsection{Tree surfaces}

The procedure to calculate the evapotranspiration of trees is based on net heat balance in the leaf-ambient interface, which is formulated as follows (Jones, 1992):

$a b s \times \cos \omega \times S_{\text {direct }}+a b s \times S_{\text {diffuse }}+\varepsilon R=\varepsilon \sigma T_{l}^{4}+h_{c}\left(T_{l}-T_{\text {in }}\right)+\lambda E$

where $a b s$ is the absorption coefficient to solar radiation, being 0.6 ; $\omega$ is the leaf orientation to direct sun's beam (fixed at $30^{\circ}$ ); $\varepsilon$ is the leaf emissivity equal to 0.96 ; $R$ is the infrared radiation emitted from leaf; $S_{\text {direct }}$ and $S_{\text {diffuse }}$ are the direct and the diffuse incident radiation on leaf surface, respectively; $h_{c}$ is the convective heat transfer coefficient in the vicinity of leaf surface; $T_{l}$ is the leaf temperature; and $\lambda$ is the evaporation latent heat, calculated using Eq. (16).

The evaporation rate is estimated as follows:

$E=\frac{\rho_{l}-\rho_{a}}{r_{l}+r_{b l}}$

where $\rho_{l}$ and $\rho_{a}$ represent the density of water vapor in ambient air and on leaf surface, respectively, computed using polynomial equations with respect to $T_{\text {in }}$ (Jones, 1992).
The terms $r_{l}$ and $r_{b l}$ stand for the leaf resistance and the leaf boundary layer resistance, respectively, defined below as:

$r_{l}=\frac{\left(r_{i a s}+r_{s t}\right) r_{c}}{\left(r_{c}+r_{i a s}+r_{s t}\right)}$

$r_{b l}=\frac{\delta_{b l}}{D_{j}}$

where $r_{\text {ias }}$ is the leaf intercellular air space resistance, fixed at a typical value $(25 \mathrm{~s} / \mathrm{m}) ; r_{s t}$ is the stomatal resistance; $r_{c}$ is the cuticular resistance, being $2500 \mathrm{~s} / \mathrm{m} ; D_{j}$ is the water-vapor mass diffusion coefficient calculated following literature guidelines (Perry \& Green, 1999); and $\delta_{b l}$ is the boundary-layer thickness on leaf surface, calculated below as:

$\delta_{b l}=K_{l}\left(\frac{w}{u_{r e f}}\right)^{1 / 2}$

where $K_{l}$ is the leaf shape parameter (equal to 4.0) and $w$ is the length of the leaf aligned to wind direction.

Based on Eq. (28), the convective heat transfer coefficient is determined as follows:

$h_{c}=\frac{K_{a i r}}{\delta_{b l}}$

where $K_{\text {air }}$ is the air's thermal conductivity being $0.0259 \mathrm{~W} / \mathrm{m} \mathrm{K}$. Obviously, the resultant evaporation rate and heat flux depend on the weather conditions for each hour of the day (Table 1 ).

\subsection{Properties of physical and construction materials}

In the present subsection, the properties of physical (plantation) and construction (ground and building) materials, as imposed in the CFD model, are reported. Specifically, the former category includes the deciduous or evergreen nature of trees and their geometry, while the latter category refers to the optical properties of the construction materials used. The aforementioned characteristics are tabulated in Tables 2 and 3.

\section{Thermal-comfort and wind-effect indices}

- Thermal comfort conditions are estimated by using the following indices (in hourly basis):

- Temperature at the height $1.80 \mathrm{~m}$ above the ground.

- Surface temperature.

- Extended PMV model for non air-conditioned spaces (Fanger \& Toftum, 2002). An expectancy factor $e=0.7$ is used.

Table 2

Tree properties.

\begin{tabular}{|c|c|c|c|c|c|}
\hline Symbol & Name & Evergreen (E)/deciduous (D) & Height (m) & Foliage shape & Foliage diameter $(\mathrm{m})$ \\
\hline T1 & Laurel & $\mathrm{E}$ & 9 & Spherical & 7 \\
\hline $\mathrm{T} 2$ & Redbud & $\mathrm{D}$ & 7 & Spherical & 6 \\
\hline T3 & Mulberry & $\mathrm{D}$ & 6 & Spherical & 5 \\
\hline $\mathrm{T} 4$ & Olive & $\mathrm{E}$ & 9 & Spherical & 7 \\
\hline T5 & Acacia & $\mathrm{D}$ & 5 & Spherical & 4.5 \\
\hline T6 & Almond & $\mathrm{D}$ & 7 & Spherical & 5 \\
\hline $\mathrm{T} 7$ & Plum & $\mathrm{D}$ & 5 & Spherical & 4.5 \\
\hline T8 & Mediterranean Cypress & $\mathrm{E}$ & 12 & Elliptical & 5 \\
\hline T9 & Arizona Cypress & $\mathrm{E}$ & 8 & Conical & 5 \\
\hline T10 & Leyland Cypress & $\mathrm{E}$ & 8 & Conical & 5 \\
\hline T11 & Sycamore & $\mathrm{E}$ & 7 & Conical & 6 \\
\hline $\mathrm{T} 12$ & Brachychiton & $\mathrm{E}$ & 5 & Conical & 3 \\
\hline T13 & Sour orange tree & $\mathrm{E}$ & 5 & Spherical & 3 \\
\hline T14 & Araucaria & $\mathrm{E}$ & 6.5 & Conical & 3 \\
\hline
\end{tabular}


Table 3

Properties of construction materials.

\begin{tabular}{|c|c|c|c|c|}
\hline Symbol & Name & Reflectivity & Emissivity & Reference \\
\hline M1 & Conventional concrete paver (dark gray) & 0.1 & 0.95 & Benzerzour, Masson, Groleau, and Lemonsu (2011) \\
\hline M2 & Conventional asphalt & 0.06 & 0.95 & Chatzidimitriou, Chrisomallidou, and Yannas (2006) \\
\hline M3 & Grey coating & 0.25 & 0.95 & Taha, Sailor, and Akbari (1992) \\
\hline M4 & Beige coating & 0.55 & 0.9 & Taha et al. (1992) \\
\hline M5 & Slate rock & 0.08 & 0.9 & Kaufman (1981) \\
\hline M6 & Grass and vegetation & 0.3 & 0.68 & Chatzidimitriou et al. (2006) \\
\hline M7 & Soil & 0.29 & 0.9 & Taha et al. (1992) \\
\hline M8 & Water & 0.05 & 0.95 & Taha et al. (1992) \\
\hline M9 & Sand & 0.24 & 0.76 & Taha et al. (1992) \\
\hline M10 & Cool paver (dark gray) & 0.52 & 0.97 & Commerce \\
\hline M11 & Cool paver (red) & 0.62 & 0.88 & Commerce \\
\hline M12 & Cool light green coating & 0.81 & 0.89 & Commerce \\
\hline M13 & Travertine marble & 0.55 & 0.9 & Dessi (2008) \\
\hline M14 & Cool gray asphalt & 0.37 & 0.89 & Commerce \\
\hline M15 & Granite paver (beige) & 0.27 & 0.9 & Taha et al. (1992) \\
\hline M16 & Planted pergolas & 0.3 & 0.68 & Chatzidimitriou et al. (2006) \\
\hline M17 & Wooden shading & 0.35 & 0.9 & Taha et al. (1992) \\
\hline M18 & Cool gray coating & 0.76 & 0.9 & Commerce \\
\hline
\end{tabular}

Wind effects on pedestrians are calculated as follows (Blocken \& Carmeliet, 2004):

Wind $_{\text {index }}=u+\sigma_{u}$

where $u$ is the velocity magnitude of the air and $\sigma_{u}$ its standard deviation (turbulence intensity). The threshold value below which acceptable wind-speed levels are considered (in urban open spaces) is $6 \mathrm{~m} / \mathrm{s}$.

Thermal comfort and wind effect calculations are performed by means of a $\mathrm{C}++$ algorithm implemented in the CFD model. The algorithm utilizes the environmental-parameters values produced by the CFD model, i.e. air temperature, mean radiant temperature, air velocity, relative humidity and turbulence intensity; hence all indices are calculated in every grid-cell of the computational domain. The personal parameters of pedestrians, used in the algorithm, include clothing insulation, being $I_{c l}=0.5 \mathrm{clo}$ and a metabolic rate fixed at $M e t=100 \mathrm{~W} / \mathrm{m}^{2}$ to account for walking users. The algorithm is described in detail in previous investigations
(Stavrakakis et al., 2008, 2010). The aforementioned procedure formulates a detailed view of the microclimate in the domain of interest, in terms of indices-values contours (bioclimatic maps). This is useful for detecting the problematic areas of the domain and for suggesting mitigation interventions.

\section{Results}

In the present section the results obtained by the computational model described above are presented. Initially, the results regarding the existing case are analyzed and discussed. Based on the local information provided, advanced bioclimatic-design interventions are proposed and the model is applied for the suggested case. The improvements obtained are illustrated in terms of differences of indices mean values before and after the architectural intervention, for each square individually as well as for the domain of interest in total. The mean values of microclimate quantities are computed as a weighted average using the area of grid-cell fronts that belong

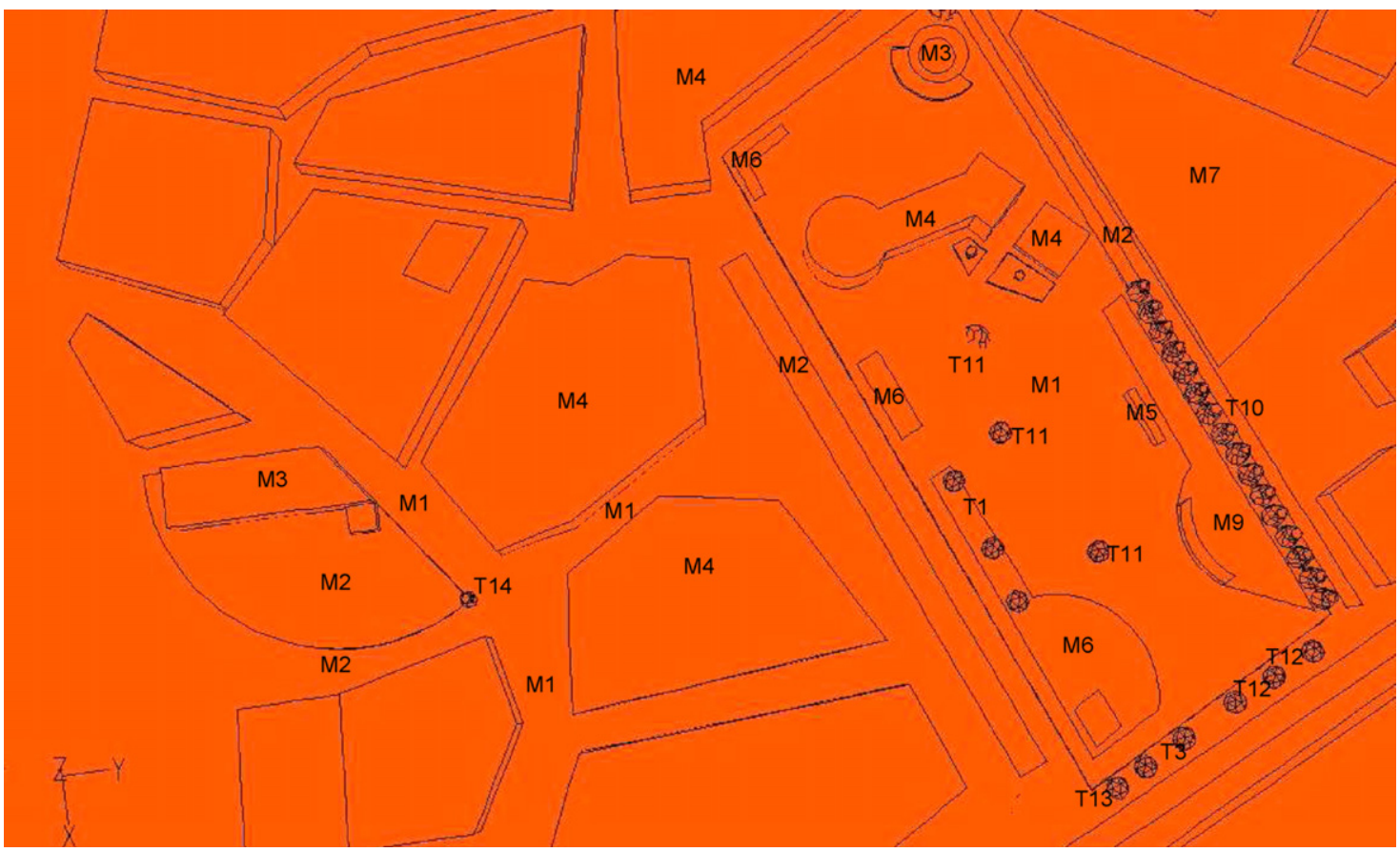

Fig. 7. Design features of the existing case. 


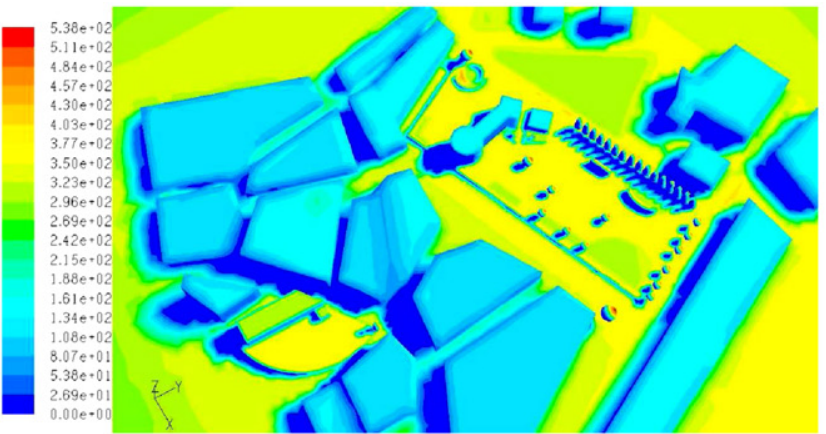

10:00

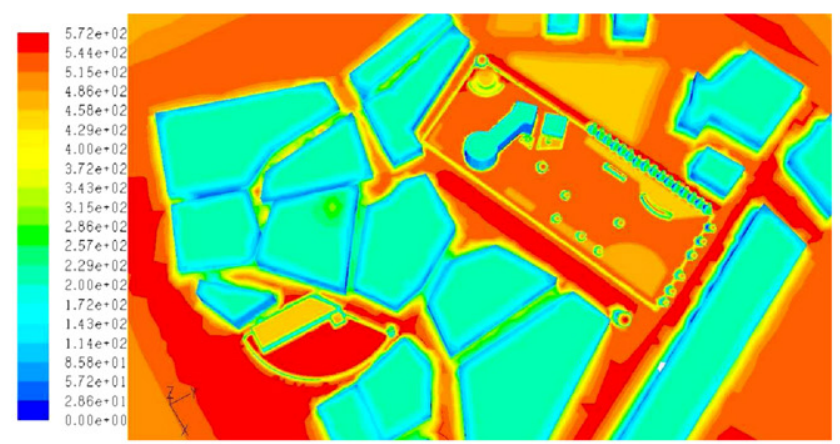

14:00

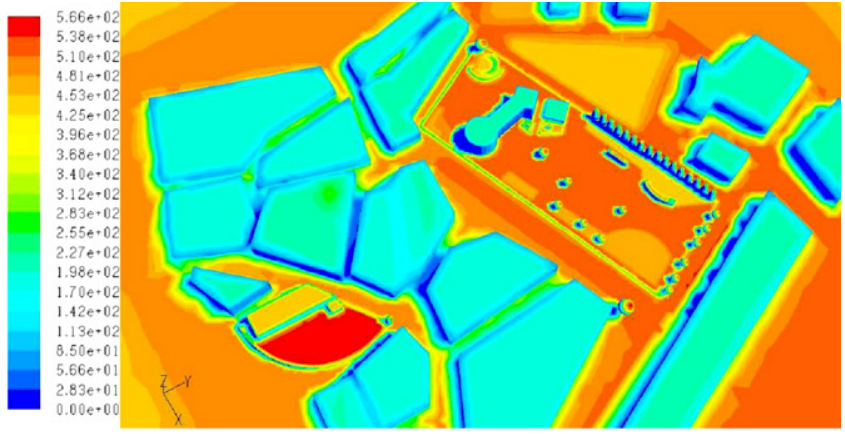

12:00

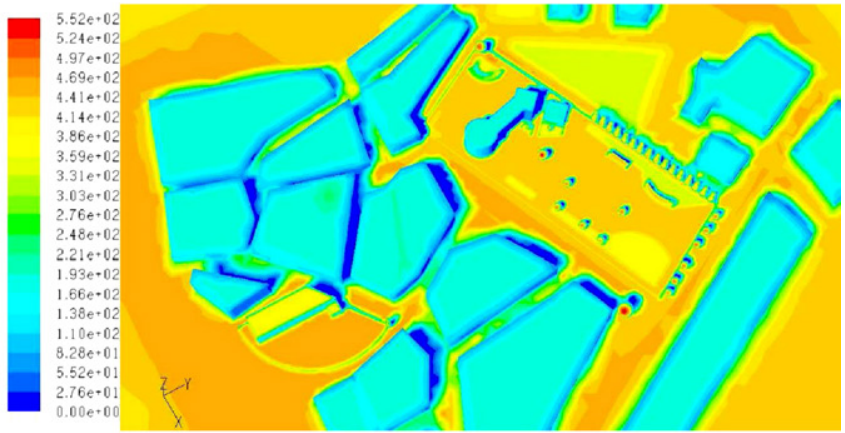

$16: 00$

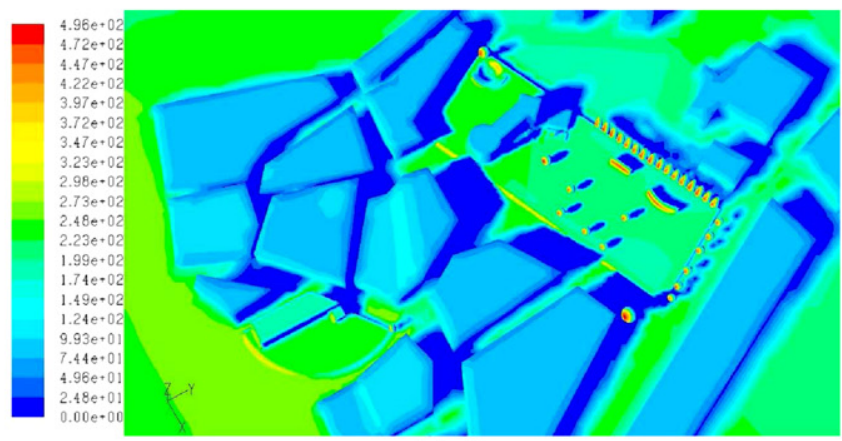

18:00

Fig. 8. Insolation "snapshots" (absorbed IR radiation $\left(W / \mathrm{m}^{2}\right)$ ) for the existing case.

to the surface of interest (square 1 , square 2 or connection road) as weighting factors. It should be mentioned that for mean-value calculations:

- The square 1 includes the main area of the square and the roads around it.

- The square 2 includes the main area of the square, the west road and the east road shown in Fig. 1.

\subsection{Existing situation}

The design features of the existing case are reported in Section 3 above. For reader convenience a description image is presented in Fig. 7 (using the symbols reported in Tables 2 and 3). The simulation is performed by applying the CFD-microclimate model analyzed in Sections 5 and 6 , with respect to each hour of the typical summer day given in Table 1.

The insolation "snapshots" in terms of absorbed IR radiation for indicative hours from 10.00 to 18.00 are presented in Fig. 8. It is obvious that both squares are not shaded adequately, while the use of conventional ground materials leads to the absorption of large amount of IR radiation, part of which is afterwards attributed to the environment. Especially in square 1, the radiation absorbed reaches maximum values due to the lack of shading, the use of conventional asphalt and the dark color of the building situated in the square. In square 2 , slightly lower values of absorbed IR radiation are obtained as a result of the existence of planted surfaces and shaded parts near trees. Regarding the connection road, it is shaded during morning hours, while it is insolated during noon and afternoon hours.

Mean temperature results at pedestrian level in the areas of interest $(1.80 \mathrm{~m})$ are presented in Fig. 9(a) from sunrise to sunset. Maximum temperature occurs at 14.00 in all areas, thus the specific hour is representative for assessing microclimate under severe heat stresses. Specifically, the highest temperature is observed in square 1 , being $33.7^{\circ} \mathrm{C}$. On the contrary, lower temperatures are calculated in square 2 and in the connection road, equal to $32.5^{\circ} \mathrm{C}$ and $32.2^{\circ} \mathrm{C}$, respectively. In Fig. 9(b), results of mean surface temperature are presented. It is seen that wall temperature is dramatically increased during noon hours for both squares, due to the lack of shading and to the use of conventional construction materials. Lower values are 
a
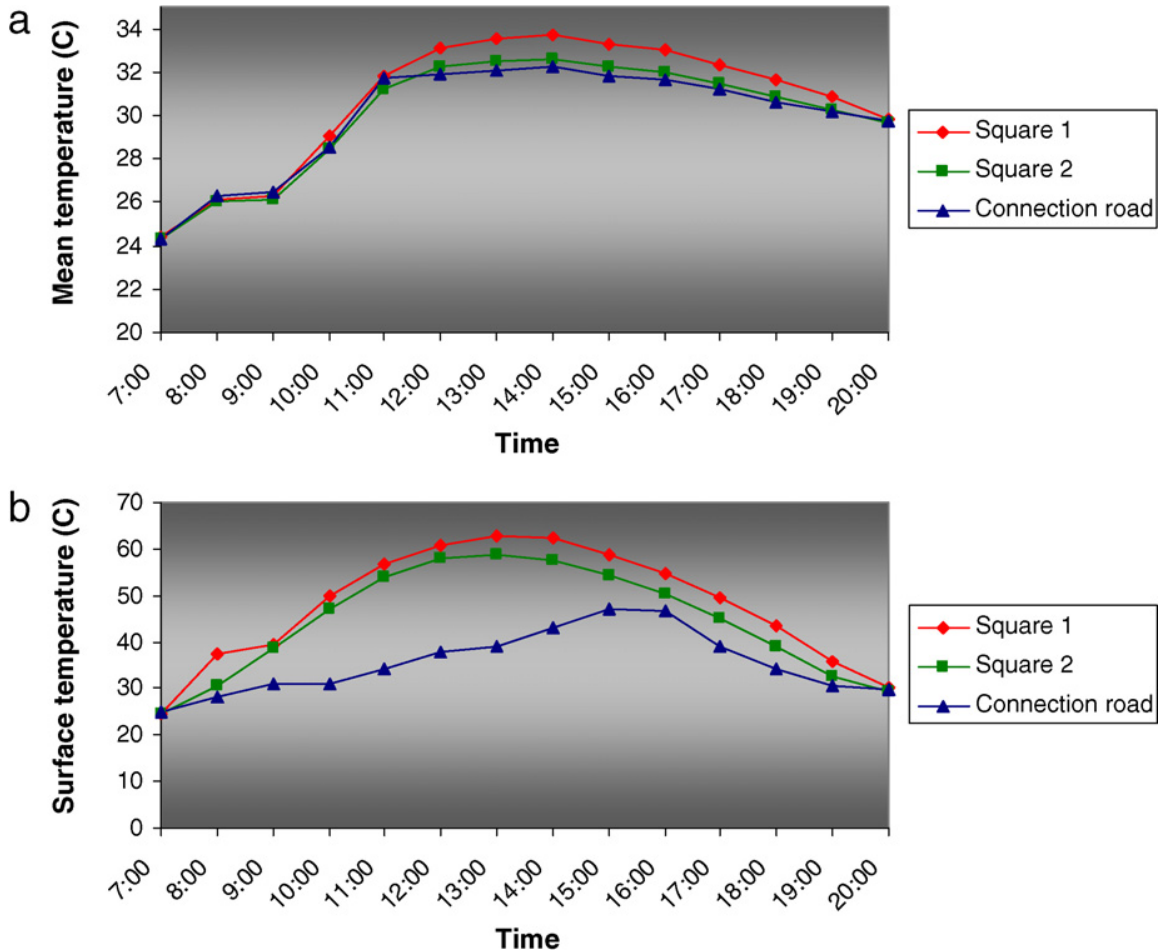

Fig. 9. (a) Mean temperature at pedestrian level and (b) mean surface temperatures in the areas of interest for the existing case.

obtained in the connection road, as it remains shaded for longer periods. An indicative view of surface temperature distribution is illustrated in Fig. 10 at 14.00. The highest temperature occurs on roads and other hard surfaces. On the contrary, on grass surfaces temperature may be even by $40^{\circ} \mathrm{C}$ lower compared to roads.

Thereinafter, results regarding microclimate at 14.00 are presented in Fig. 11. Specifically, distributions of PMV and Wind ${ }_{\text {index }}$ at pedestrian level are illustrated. The following conclusions are drawn:

- Square 1: Intensive thermal discomfort throughout the square (mean value of PMV: 2.9) due to high temperature dominating in the area. Wind effects on pedestrians are within acceptable levels (mean value of Wind $_{\text {index }}: 1.47$ ).

- Square 2: Thermal discomfort due to high temperatures (mean value of PMV: 2.29), especially at the south part of the square. Wind effects are considered relatively intense at the semioutdoor space of the city-hall building (Wind $_{\text {index }}$ ranges from
$4.4 \mathrm{~m} / \mathrm{s}$ to $5.8 \mathrm{~m} / \mathrm{s}$ ). Wind strength may exceed acceptable levels at the play-ground area, where the index Wind $_{\text {index }}$ ranges from $5.8 \mathrm{~m} / \mathrm{s}$ to $7.17 \mathrm{~m} / \mathrm{s}$.

- Connection road: Lower values of $P M V$ are obtained (mean value: 2.05) compared to the aforementioned areas, but still hot conditions prevail. Regarding wind effects, moderate wind strength occurs (mean value of Wind $_{\text {index }}: 2.36 \mathrm{~m} / \mathrm{s}$ ).

\subsection{Suggested architectural intervention}

Based on the problematic areas detected above, mitigation bioclimatic-design interventions are formulated. The physical and construction elements of the proposal are described schematically in Fig. 12. The suggested design intervention involves techniques to increase shading areas, to reduce temperature at the non-shaded parts and to ensure wind protection in areas frequently used by pedestrians (semi-outdoor space and play-ground). Specifically, the interventions proposed include:

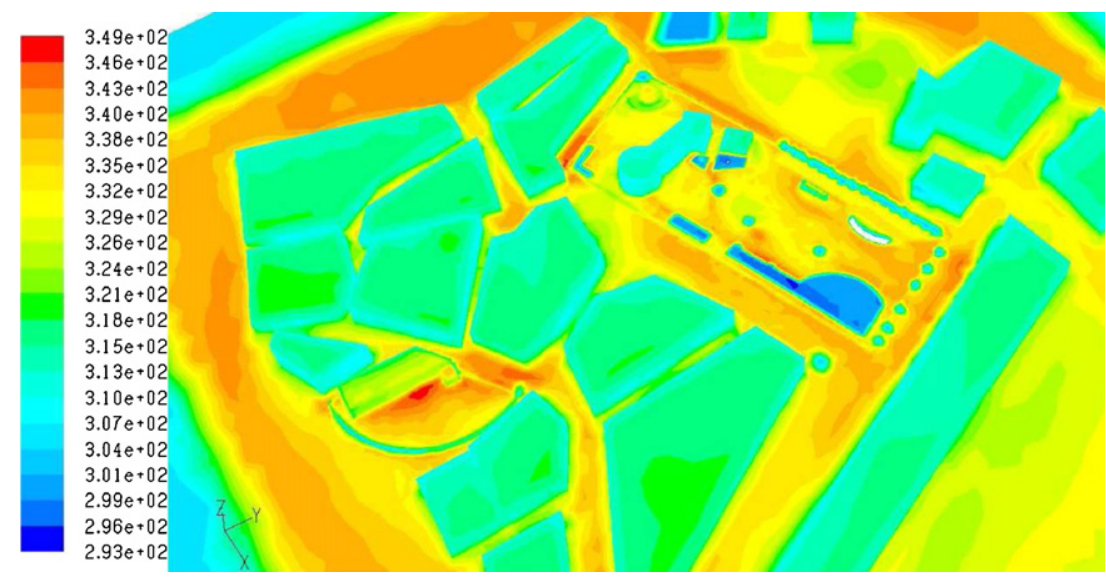

Fig. 10. Surface temperature $(\mathrm{K})$ at 14.00 for the existing case. 
$P M V$

a

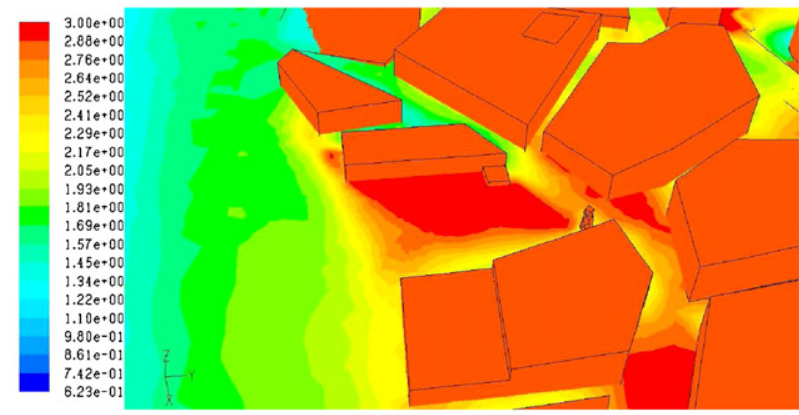

b

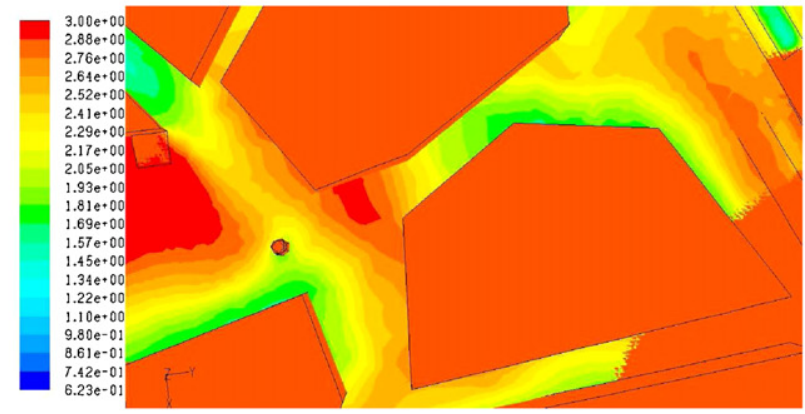

C

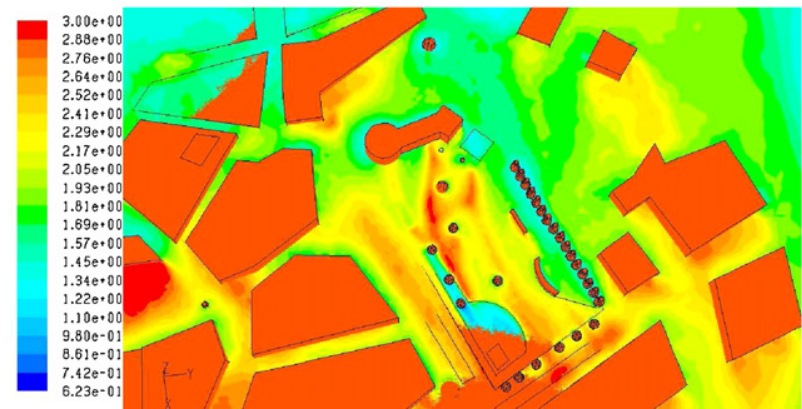

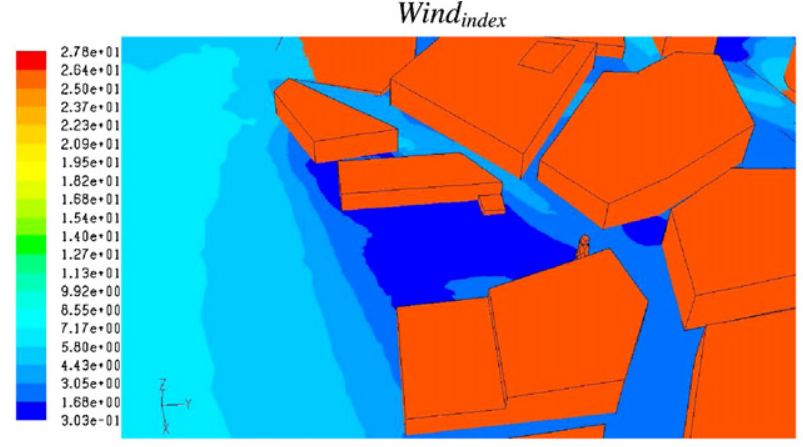
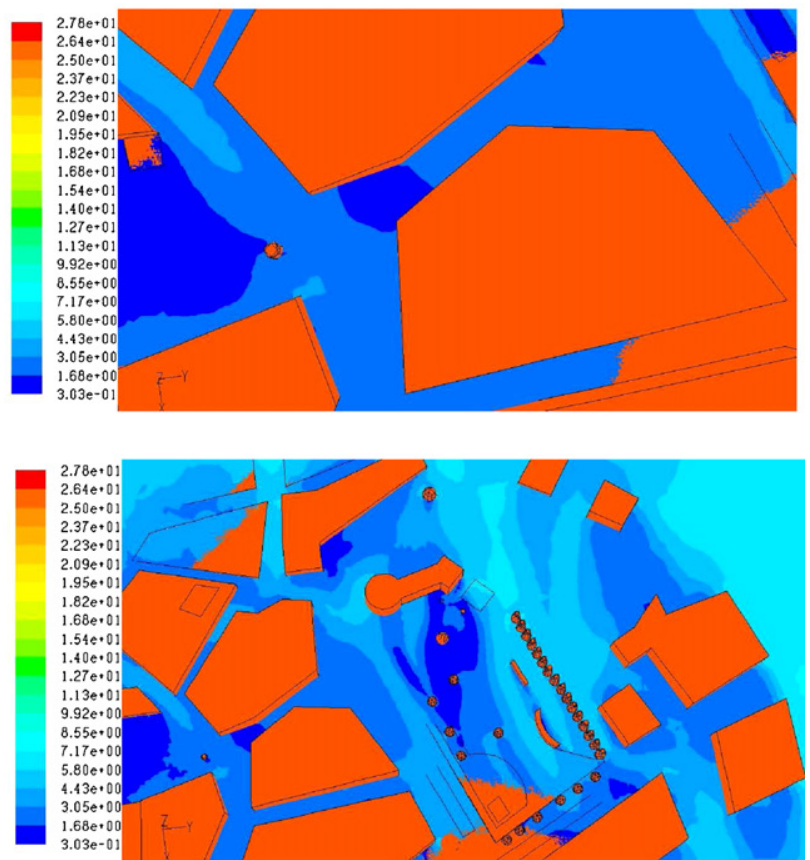

Fig. 11. Distributions of PMV and Wind index $_{\text {at }}$ at pedestrian level in: (a) square 1, (b) connection road and (c) square 2, for the existing case.

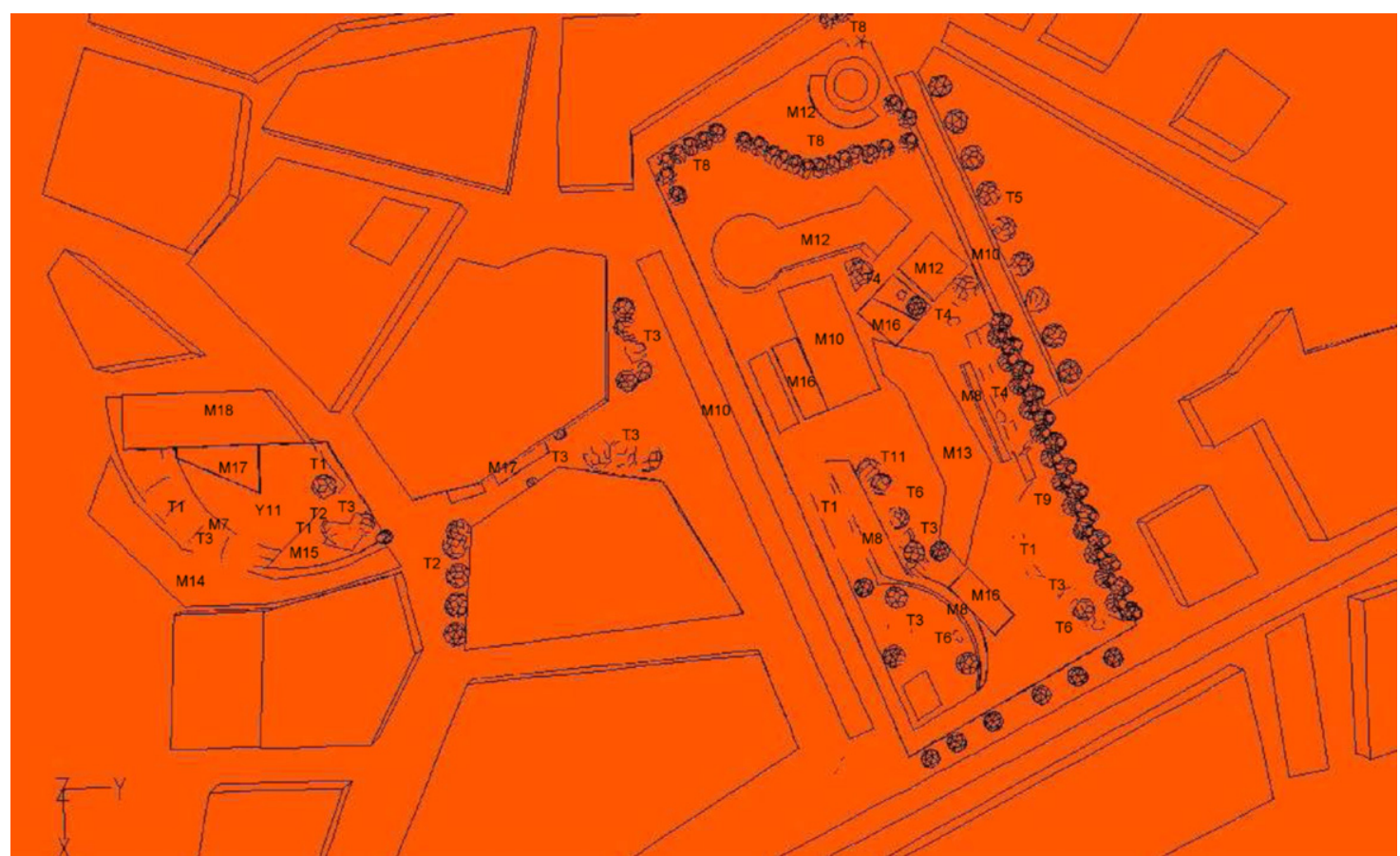

Fig. 12. Design features of the suggested case. 


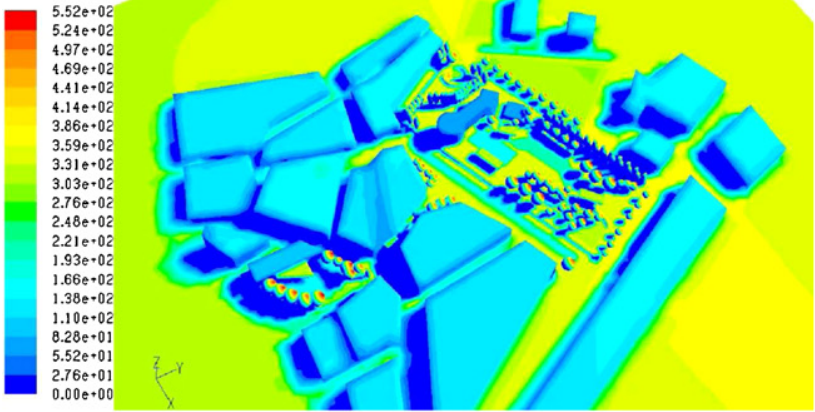

10:00

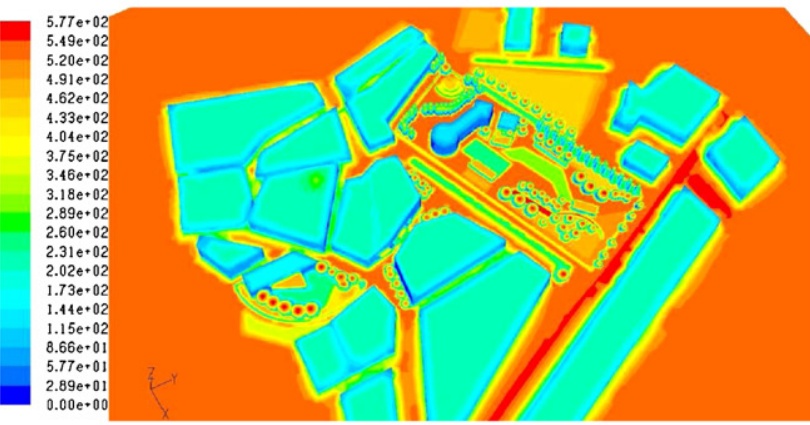

14:00

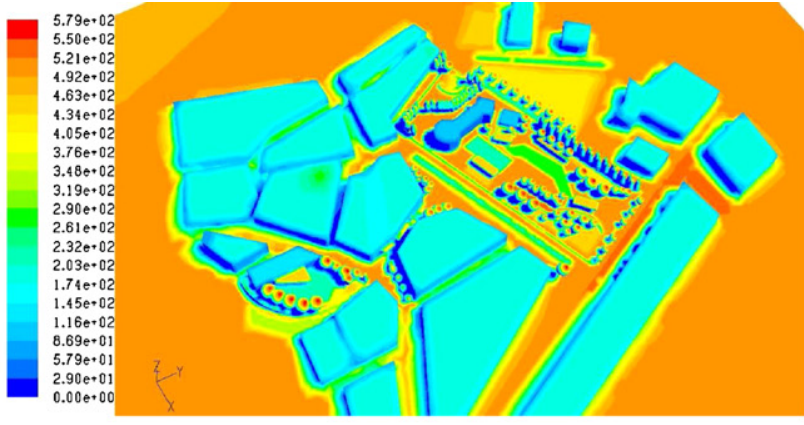

12:00

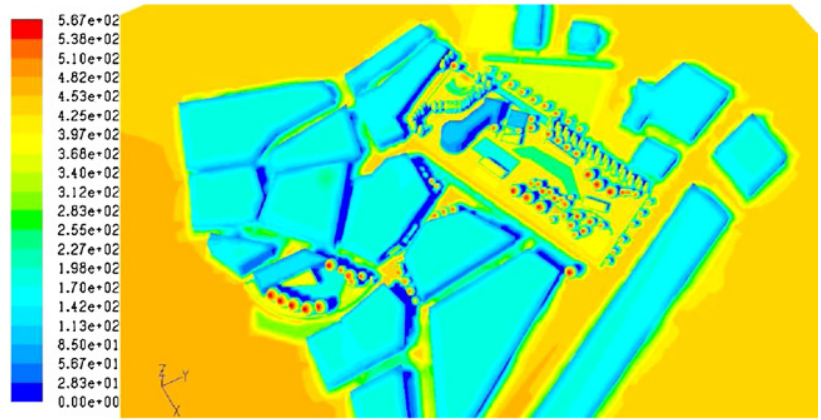

16:00

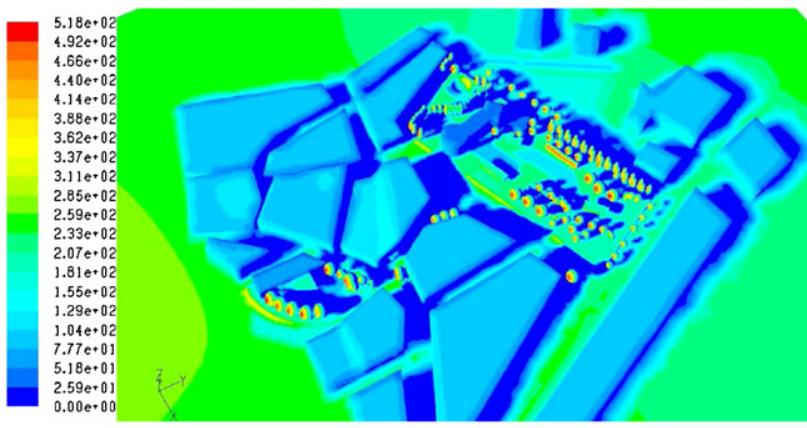

18:00

Fig. 13. Insolation "snapshots" (absorbed IR radiation $\left(\mathrm{W} / \mathrm{m}^{2}\right)$ ) for the suggested case.

- Square 1: (a) Construction elements: Cool red paver in the main area of the square, granite paver around the square, cool gray asphalt at the west and south neighboring roads, grass parterre and compressed soil in the west part of the square, wooden shading and cool gray coating on the building. (b) Physical elements: Mainly laurel, redbud and mulberry have been used.

- Square 2: (a) Construction elements: Arc lining of travertine marble, cool gray paver at the south part of the building as well as at the neighboring roads, cool green coating on building facades and on auditorium surfaces. (b) Physical elements: Planted pergolas and water streams, Mediterranean-cypress cluster at the north part of the square for wind protection of the semi-outdoor space, Arizona cypress for enhancing wind protection and shading at the play ground, olive, redbud, laurel, mulberry, almond and sycamore.

- Connection road: (a) Construction elements: Wooden shading devices. (b) Physical elements: Mainly redbud and mulberry are used.

The insolation "snapshots" for the suggested case are presented in Fig. 13. Compared to the existing situation, the absorbed IR radiation is substantially reduced as a result of applying physical and artificial shading devices and cool materials. The impact of the aforementioned situation is obvious in mean surface temperature and in mean temperature at pedestrian level during the day cycle (Fig. 14). Maximum temperature now occurs in square 2 at 14.00 , being lower than that in the existing case by $1.5^{\circ} \mathrm{C}$. Regarding the square 1 and the connection road, temperature is reduced by $3.64^{\circ} \mathrm{C}$ and $1.6^{\circ} \mathrm{C}$, respectively, at the same hour. Fig. 16 dictates that mean surface temperature is reduced by $26^{\circ} \mathrm{C}, 11^{\circ} \mathrm{C}$ and $5.5^{\circ} \mathrm{C}$, in square 1 , square 2 and connection road, respectively. An indicative view of surface temperature distribution is illustrated in Fig. 15 at 14.00 .

The effect of the interventions suggested is shown in Fig. 16, where results of PMV and $W_{i n d}$ index $_{\text {at }} 14.00$ are presented. The following conclusions are derived:

- Square 1: Thermal comfort levels are substantially improved (mean PMV equals to 1.37). Wind intensity remains at low levels as in the existing case.

- Square 2: Improvement of thermal comfort (mean PMV equals to 1.76 ), especially along north, east and west side of the square. 

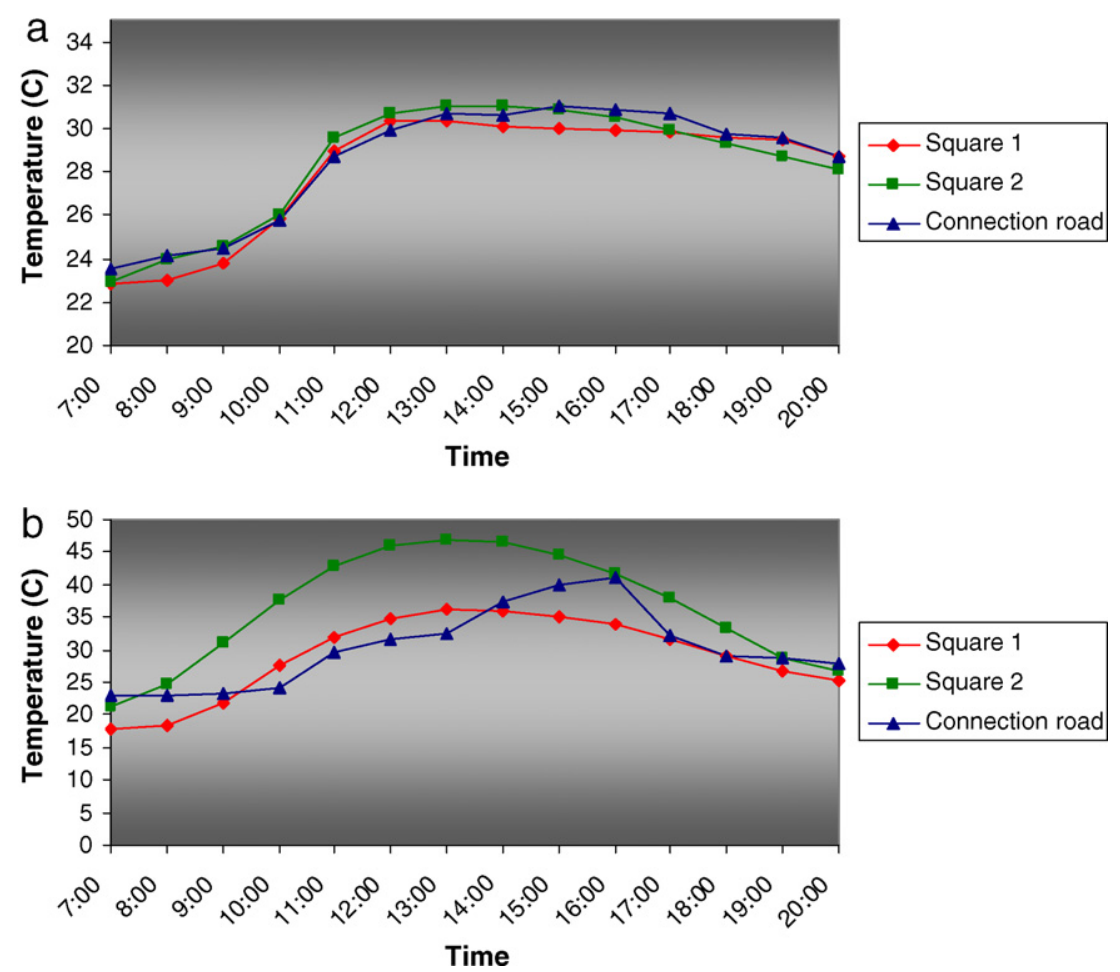

Fig. 14. (a) Mean temperature at pedestrian level and (b) mean surface temperature in the areas of interest for the suggested case.

Referring to wind effects the mean value of Wind $_{\text {index }}$ is reduced to $0.5 \mathrm{~m} / \mathrm{s}$ and to $3.5 \mathrm{~m} / \mathrm{s}$ at the semi-outdoor space and at the playground area, respectively, as a result of the vegetation added in the north and the east part of the square.

- Connection road: Improvement of thermal comfort levels (mean value of $P M V$ : 1.73). Wind effects remain at the same level as in the existing case.

\subsection{Comparative results}

In the present subsection, the improvements obtained are illustrated in terms of differences of microclimate parameters between the existing and the suggested situation.
7.3.1. Mean surface-temperature and temperature differences at pedestrian level

The hourly differences in mean temperature at pedestrian level and surface temperature in the areas of interest (squares and connection road) are calculated by exploiting Figs. 9 and 14 for the existing and the suggested case, respectively. The results are illustrated in Figs. 17 and 18. It is seen that mean temperature at $1.80 \mathrm{~m}$ above the ground is reduced by at least $1.5^{\circ} \mathrm{C}$ in the squares during most hours of the day. The same is not true in the connection road as it is being shaded in longer periods compared to the squares. Regarding surface temperature, it is reduced by at least $5^{\circ} \mathrm{C}$ during most hours in the areas of interest.

As far as the difference of mean maximum temperatures is concerned it is concluded that at pedestrian level, maximum temperature (occurred at 14.00 ) is reduced by $3.35^{\circ} \mathrm{C}, 1.52^{\circ} \mathrm{C}$ and $1.2^{\circ} \mathrm{C}$,

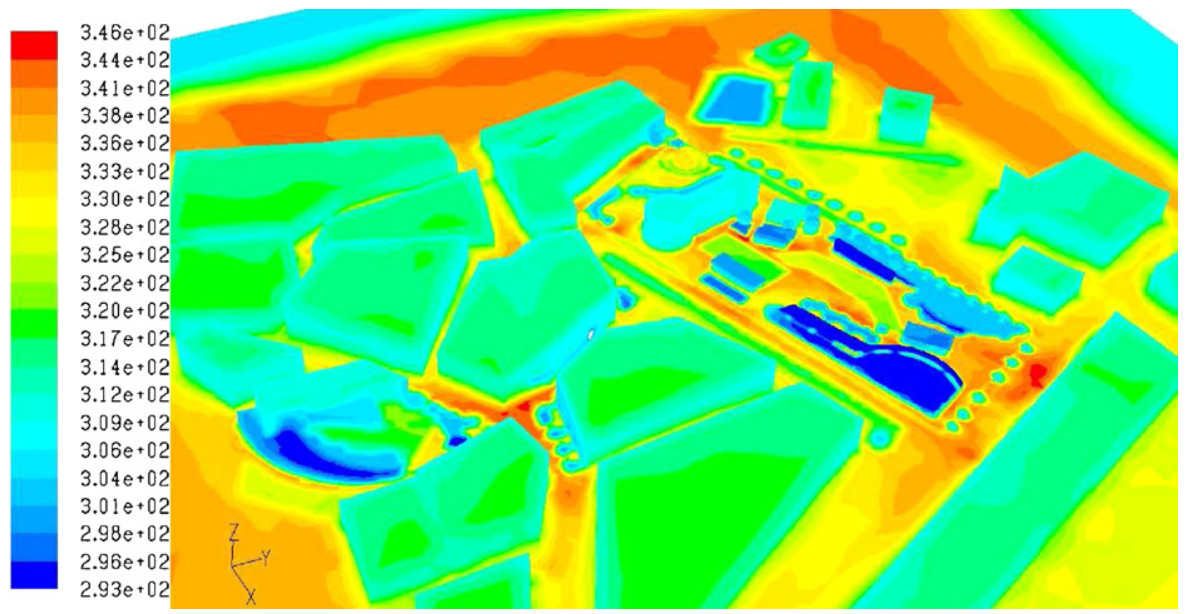

Fig. 15. Surface temperature $(K)$ at 14.00 for the suggested case. 

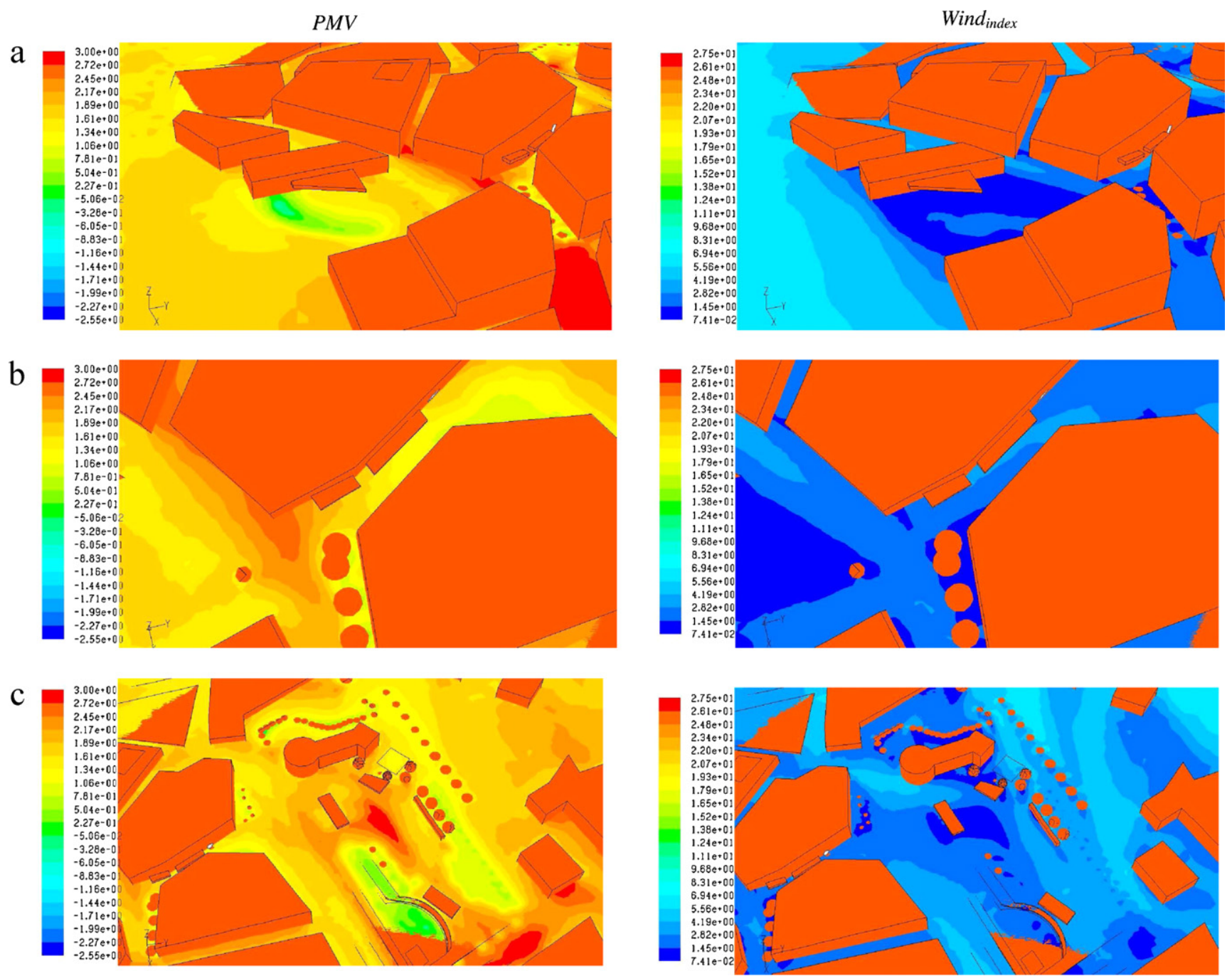

Fig. 16. Distributions of PMV and Wind $_{\text {index }}$ at pedestrian level in: (a) square 1 , (b) connection road and (c) square 2 , for the suggested case.

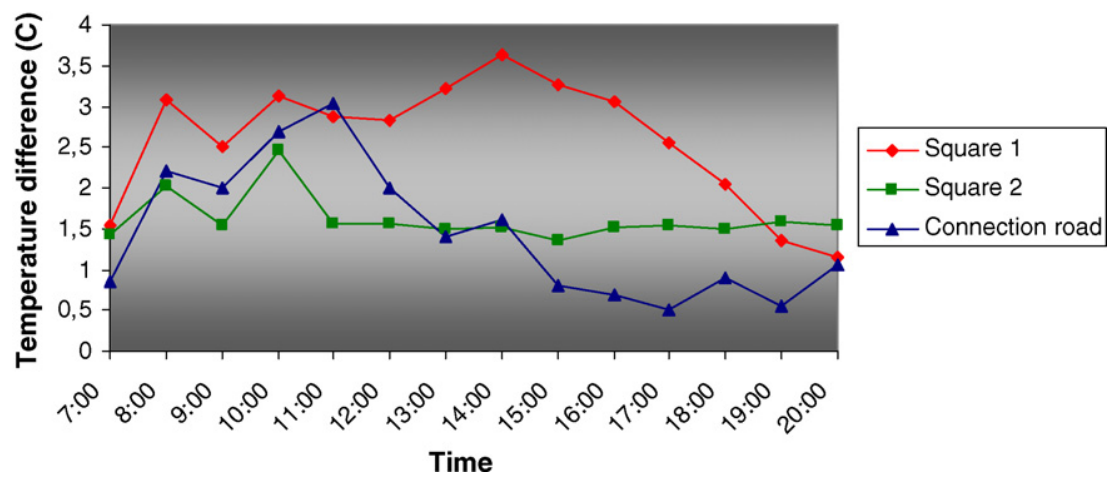

Fig. 17. Mean temperature difference between the existing and suggested case at pedestrian level in the areas of interest.

in the square 1 , square 2 and the connection road, respectively. Referring to mean maximum surface temperature, the respective reduction occurred is $26^{\circ} \mathrm{C}, 12^{\circ} \mathrm{C}$ and $6^{\circ} \mathrm{C}$.

\subsubsection{Thermal comfort and draught improvements}

The same calculation procedure as above is followed concerning the improvements obtained for thermal comfort (PMV) and draught $\left(\right.$ Wind $\left._{\text {index }}\right)$ indices, during the hours of severe heat stresses and wind effects (10.00-18.00) (see Table 1). The differences between the existing and the suggested case are presented in percentage terms. The results of both indices are illustrated in Fig. 19. It is concluded that especially in the squares, the PMV index is reduced by at least $20 \%$ during all hours. Regarding the draught index, the change is negligible in the square 1 and in the connection road as they are not subjected in wind stresses in any case. On the contrary, a reduction of at least $20 \%$ is obtained in square 2 as a result of targeted interventions applied, i.e. in the semi-outdoor space in the city-hall building and in the playground area. 


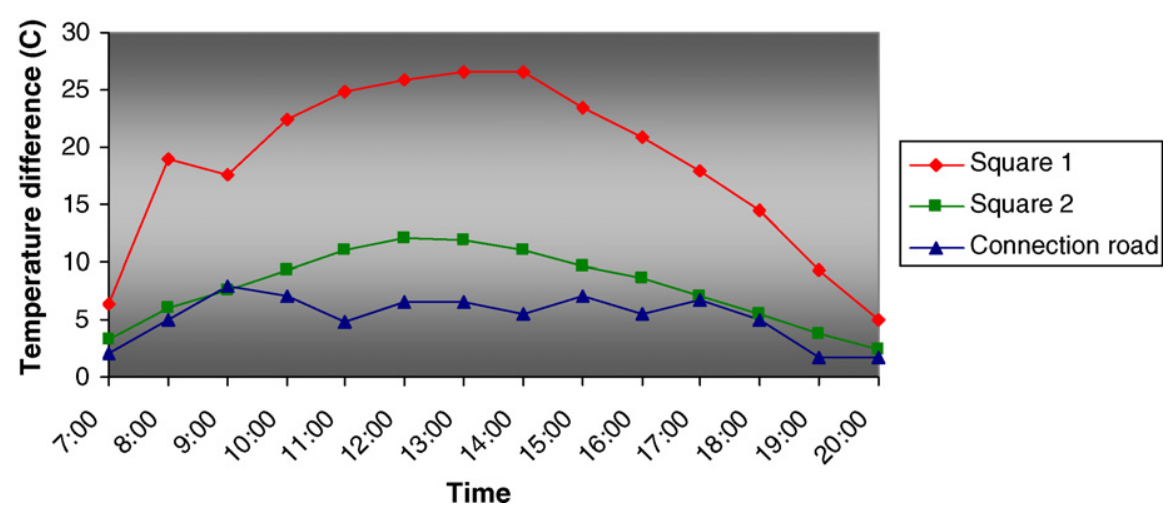

Fig. 18. Mean surface-temperature difference between the existing and suggested case in the areas of interest.
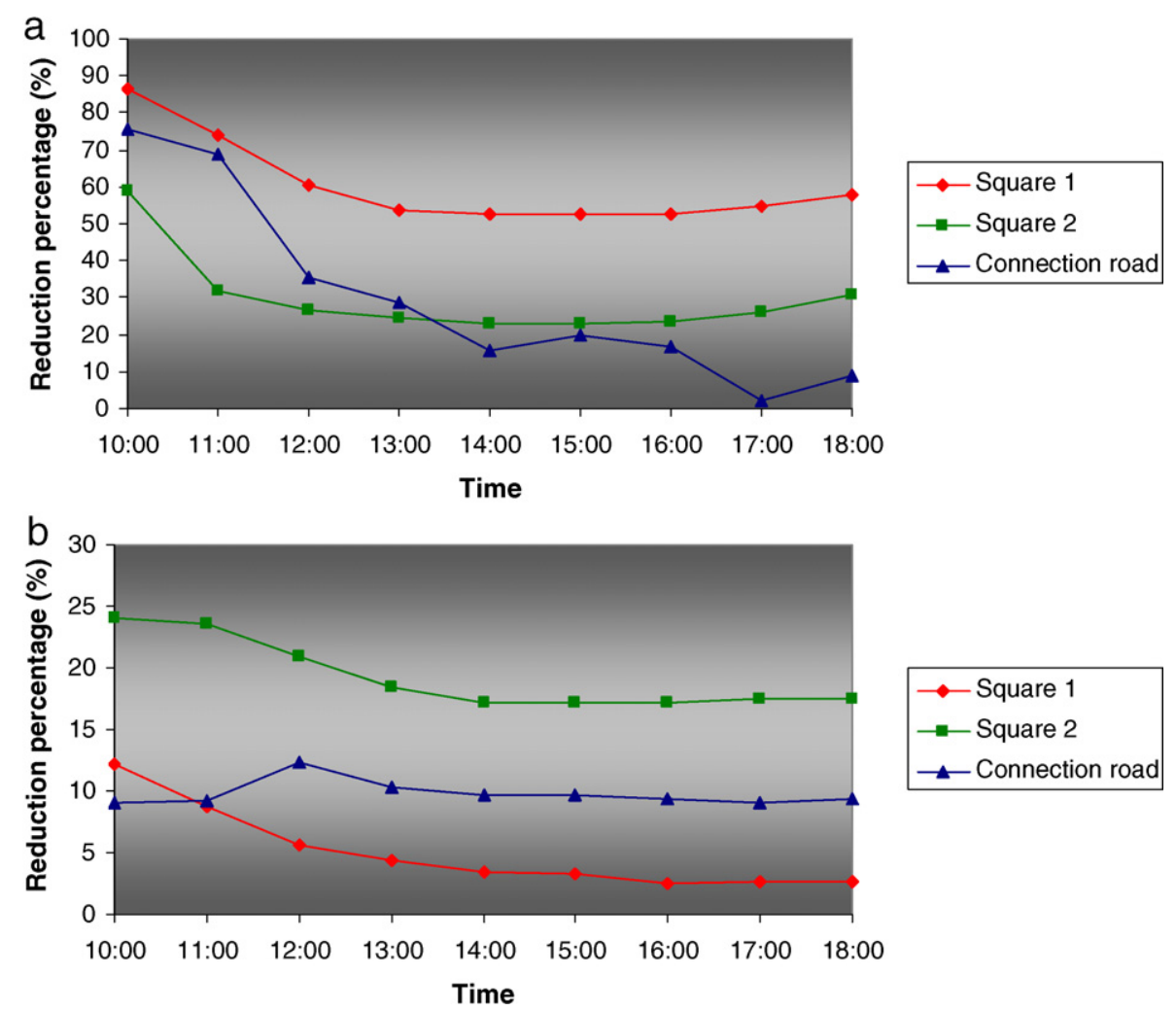

Fig. 19. Reduction percentage of: (a) PMV and (b) Wind $_{\text {index }}$, in the suggested case.

\section{Conclusions}

In the present work a general computational methodology for assessing and mitigating Urban Heat Island is developed. A special CFD model is described which is used to quantify microclimate and comfort conditions in the urban environment. The effects of both construction and physical elements are taken into account and local information in detailed resolution regarding the aforementioned conditions is obtained. The usefulness of the computational model lies on the fact that it can be applied for assessing the existing case and extracting the problematic areas and for testing any architectural interventions suggested for eliminating those areas. The conclusions of the analysis presented herein are summarized as follows:

- Environmental and microclimate conditions are quantified throughout the domain of interest before and after the architectural intervention.
- The results obtained provide the problematic areas (UHI and wind effects) based on which the designer proposes interventions.

- The effectiveness of any architectural intervention may be tested before construction, and the best design is finally decided through trial and error.

- For the specific case considered it is concluded that mean temperature at the pedestrian level is reduced by at least $1.5^{\circ} \mathrm{C}$ in the squares during hours of severe thermal stress. During the same period, mean surface temperature is reduced by at least $12^{\circ} \mathrm{C}$. These reductions lead to an improvement in thermal comfort by at least $20 \%$, representing an adequate mitigation of UHI in the urban domain.

- It is expected that the mitigation of thermal stresses reduce energy consumption for cooling purposes in neighboring buildings; thus it contributes to the reduction of carbon emissions.

- The methodology described may contribute in developing guidelines and standards for retrofitting open public spaces and in stimulating scientists and engineers to conduct advanced 
technical studies at the horizon of future initiatives such as "ecoquartiers" and "smart cities".

\section{Acknowledgement}

The authors wish to acknowledge the financial contribution of the Municipality of Malevizi, Greece.

\section{References}

Akbari, H., Davis, S., Dorsano, S., Huang, J., \& Winert, S. (1992). Cooling our communities - A guidebook on tree planting and white coloured surfacing. US Environmental Protection Agency: Office of Policy Analysis, Climate Change Division.

Benzerzour, M., Masson, V., Groleau, D., \& Lemonsu, A. (2011). Simulation of the urban climate variations in connection with the transformations of the city of Nantes since the $17^{\text {th }}$ century. Building and Environment, 46, 1545-1557.

Blocken, B., \& Carmeliet, J. (2004). Pedestrian wind environment around buildings: Literature review and practical examples. Journal of Thermal Envelope and Building Science, 28, 107-159.

Bouyer, J., Inard, C., \& Musy, M. (2011). Microclimatic coupling as a solution to improve building energy simulation in an urban context. Energy and Buildings, $43,1549-1559$

Chatzidimitriou, A., Chrisomallidou, N., \& Yannas, S. (2006). Ground surface materials and microclimates in urban open spaces. In The 23rd conference on passive and low energy architecture (PLEA) Geneva, Switzerland, 6-8 September 2006,

Chlela, F., Hassaunndee, A., Inard, C., \& Riederer, P. (2009). A new methodology for the design of low energy buildings. Energy and Buildings, 41, 982-990.

Cook, N. J. (1997). The Deavis and Harris ABL model applied to heterogeneous terrain. Journal of Wind Engineering and Industrial Aerodynamics, 66, 197-214.

Dessi, V. (2008). Use of simplified tools to evaluate thermal comfort in urban spaces in the teaching experience. In 25th Conference on Passive and Low Energy Architecture (PLEA) Dublin, 22 and 24 October 2008.

Doulos, L., Santamouris, M., \& Livada, I. (2001). Passive cooling of outdoor urban spaces. The role of materials. Solar Energy, 77, 231-249.

Fanger, P. O., \& Toftum, J. (2002). Extension of the PMV model to non-air-conditioned buildings in warm climates. Energy and Buildings, 34, 533-536.

Ferziger, J. H., \& Peric, M. (2002). Computational methods for fluid dynamics (3rd ed.). New York: Springer-Verlag.

Fintikakis, N., Gaitani, N., Santamouris, M., Assimakopoulos, M., Assimakopoulos, D. N., Fintikaki, M., et al. (2011). Bioclimatic design of open public spaces in the historic centre of Tirana, Albania. Sustainable Cities and Society, 1, 54-62.

Fluent, Inc. (2005). Fluent User's Guide, Version 6.2. Lebanon, NH, USA: Fluent Inc.

Hassid, S., Santamouris, M., Papanikolaou, N., Linardi, A., Klitsikas, N., Georgakis, C., et al. (2000). The effect of the Athens heat on the air conditioning load. Energy and Buildings, 32(2), 131-141.

Jain, P. C. (1988). Accurate computations of monthly average daily extraterrestrial irradiation and the maximum possible sunshine duration. Solar and Wind Technology, 5, 41-53.

Jones, H. G. (1992). Plants and microclimate-A quantitative approach to environmental plant physiology (2nd ed.). England: Cambridge University Press.

Kaufman, J. E. (1981). IES lighting handbook, Reference volume. New York: Illuminating Engineering Society of North America.

Launder, B. E., \& Spalding, D. B. (1972). Mathematical models of turbulence. Academic Press.

Launder, B. E., \& Spalding, D. B. (1974). The numerical computation of turbulent flows. Computer Methods in Applied Mechanics and Engineering, 3, 269-289.
Memon, R. A., Leung, D. Y. C., \& Chunho, L. (2008). A review on the generation determination and mitigation of Urban Heat Island. Journal of Environmental Sciences, 20, $120-128$.

Monteith, J. L. (1965). Evaporation and environment. Symposia of the Society for Experimental Biology, 19, 205-224.

Niachou, A., Livada, I., \& Santamouris, M. (2008). Experimental study of temperature and airflow distribution inside an urban street canyon during hot summer weather conditions. Building and Environment, 43, 1383-1392.

Patankar, S. V. (1980). Numerical heat transfer and fluid flow. Hemisphere: Washington.

Penman, H. L. (1948). Natural evaporation from open water, bare soil and grass. Proceedings of the Royal Society of London, Series A, 194, 120-145.

Perry, R. H., \& Green, D. W. (1999). Perry's chemical engineers' handbook. New York: McGraw-Hill.

Priyadarsini, R., Hien, W. N., \& David, C. K. W. (2008). Microclimatic modelling of the urban thermal environment of Singapore to mitigate urban heat island. Solar Energy, 82, 727-745.

Richards, P. J., \& Hoxey, R. P. (1993). Appropriate boundary conditions for computational wind engineering models using the k-(turbulence model. Journal of Wind Engineering and Industrial Aerodynamics, 46-47, 145-153.

Robitu, M., Musy, M., Inard, C., \& Groleau, D. (2006). Modeling the influence of vegetation and water pond on urban microclimate. Solar Energy, 80, 435-447.

Santamouris, M., Pavlou, K., Synnefa, A., Niachou, K., \& Kolokotsa, D. (2007). Recent progress on passive cooling techniques. Advanced technological developments to improve survivability levels in low-income households. Energy and Buildings, 39, 859-866.

Santamouris, M., Synnefa, A., \& Karlessi, T. (2011). Using advanced cool materials in the urban built environment to mitigate heat islands and improve thermal comfort conditions. Solar Energy, 85, 3085-3102.

Stavrakakis, G. M., \& Markatos, N. C. (2009). Simulation of airflow in one- and tworoom enclosures containing a fire source. International Journal of Heat and Mass Transfer, 52, 2690-2703.

Stavrakakis, G. M., Koukou, M. K., Vrachopoulos, M. Gr., \& Markatos, N. C. (2008). Natural cross-ventilation in buildings: Building-scale experiments numerical simulation and thermal comfort evaluation. Energy and Buildings, 40, 1666-1681.

Stavrakakis, G. M., Stamou, A. I., \& Markatos, N. C. (2009). Evaluation of thermal comfort in indoor environments using Computational Fluid Dynamics (CFD). In R. G. Harris, \& D. P. Moore (Eds.), Indoor work and living environments: Health, safety and performance (pp. 97-166). New York: Nova Science Publishers Inc.

Stavrakakis, G. M., Tomazinakis, N. M., \& Markatos, N. C. (2011). Modified closure constants of the Standard k- $\varepsilon$ turbulence model for the prediction of wind-induced natural ventilation. Building Services Engineering Research and Technology, http://dx.doi.org/10.1177/0143624411407950

Stavrakakis, G. M., Zervas, P. L., Sarimveis, H., \& Markatos, N. C. (2010). Development of a computational tool to quantify architectural-design effects on thermal comfort in naturally ventilated rural houses. Building and Environment, 45, 65-80.

Taha, H., Sailor, D., \& Akbari, H. (1992). High-albedo materials for reducing building energy use. California: Energy and Environment Division, Lawrence Berkeley Laboratory, University of California.

Takahashi, K., Yoshida, H., Tanaka, Y., Aotake, N., \& Wang, F. (2004). Measurement of thermal environment in Kyoto city and its prediction by CFD simulation. Energy and Buildings, 36, 771-779.

Versteeg, H. K., \& Malalasekera, W. (1995). An introduction to computational fluid dynamics - The finite volume method. England: Longman Group Ltd.

White, P., Golden, J. S., Biligiri, K. P., \& Kaloush, K. E. (2010). Modeling climate change impacts of pavement production and construction. Resources, Conservation and Recycling, 54, 776-782. 